\title{
Fractal Markets, Frontiers, and Factors
}

\author{
Wilhelm Berghorn ${ }^{1}$, Martin T. Schulz ${ }^{2} \&$ Sascha Otto $^{3}$ \\ ${ }^{1}$ Mandelbrot Asset Management GmbH, Erlangen, Germany \\ ${ }^{2}$ University of Applied Sciences, Aschaffenburg, Germany \\ ${ }^{3}$ Die Sparkasse Bremen AG, Bremen, Germany \\ Correspondance: Wilhelm Berghorn, Mandelbrot Asset Management GmbH, Erlangen, Germany.
}

Received: January 21, 2021

Accepted: March 3, 2021

Online Published: September 2, 2021

doi:10.5430/ijfr.v12n5p104

URL: https://doi.org/10.5430/ijfr.v12n5p104

\begin{abstract}
We develop an alternative view to the modern finance theory that essentially suggests equilibria in efficient markets by taking a risk-based view of asset returns in stock markets. Based on a mathematical analysis of stock market data using multi-scale approaches, we will alternatively describe markets and factors as trend-based fractal processes and analyze well-known factor premiums, which leads to a return-based view of markets and a model of investors reacting to market environments. We conclude that markets could be viewed alternatively as fractal, non-stationary and, at most, asymptotically efficient.
\end{abstract}

Keywords: momentum effect, low volatility effect, value effect, size effect, efficient market theory, Mandelbrot, fractional Brownian motion, fractal markets

\section{Introduction}

Are markets efficient, as suggested by Fama (1970)? To date, several developments in modern finance come to very different conclusions. In order to support our central claim that one can easily built an alternative view we first review relevant historical literature which builds todays financial theory. Efficiency is based on statistical independence of asset returns. However, as we review in Section 1.2. there is a vast amount of empirical research showing that certain measurable ,factors' influence the future development of asset returns. Also from the mathematical side (as reviewed in Section 1.3) there is work showing that statistical independence is violated. In Section 1.4. we state the basis of our own work that scale (meaning the time horizon) does matter when analysing phenomena which is essentially is the building block for connecting these different observations.

\subsection{Historical Summary}

Core to the hypothesis are several historical steps, which can be rooted in Bachelier's (1900) and Einstein's (1905) random process models, particularly the geometric Brownian motion. While Albert Einstein modeled molecule movements, Bachelier used these processes to develop an option pricing theory. In his research, Fama (1995) summarized the previous work of Cootner (1964), Fama (1965), Kendall and Hill (1953), and Moore (1962) by stating the independence of price changes. This viewpoint was even supported by the work of Granger and Morgenstern (1963) using spectral analysis - but only for the short run. These key mathematical properties were in line with the general findings by Markowitz (1952), who is seen as the founder of modern portfolio theory. In his work, he theorised investors beeing rational by assuming that they should incorporate (discounted) expected returns and covariances in their investment decisions. With the efficient frontier, it was possible for Sharpe (1964) and Lintner (1965) to independently formulate the capital asset pricing model, introducing a risk modeling approach using beta as a risk factor. Sharpe (1964) documented that '[...] investors are assumed to agree on the prospects of various investments - the expected values, standard deviations and correlation coefficients. [ ... ] Needless to say, these are highly restrictive and undoubtedly unrealistic assumptions.' (p. 433-434) Under these assumptions, he showed how equilibrium could be achieved. As soon as investors (with specific risk tolerance) realize inefficient portfolios, they can switch to efficient ones. Fama, Fisher, Jensen and Roll (1969) showed how quickly (or efficiently) stock market prices can react to new information, which is consistent with the Efficient Market Hypothesis (EMH) of Fama (1970). The independence claim of that theory finally leads to the important application of the option-pricing model of Black and Scholes (1973). 
Concerning the capital asset pricing model, empirical tests for verification were carried out by Fama and MacBeth (1973), where the underlying model of a linear relationship between risk and return could not be rejected. In more recent empirical studies, this risk-based view was extended by Fama and French (1992), and Fama and French (2008) using mainly the 'value effect' and the 'size effect' for a risk-based explanation of asset returns. With growing numbers of further studies showing excess returns, the 5-factor model was introduced by Fama and French (2015). Blitz et al (2018) criticized that some of these factors do not have a risk-based explanation, and proposed to extend these models by incorporating low volatility and momentum.

\subsection{Factors}

An increasing number of factors affect future asset returns. Theoretically important is the low volatility effect, i.e., companies with lower risk estimates have higher risk-adjusted returns, essentially contradicting the capital asset pricing model, which states the opposite. Observations of this effect originated in Friend and Blume (1970) and Black, Jensen and Scholes (1972) and were continued by Haugen and Heins (1975) and Frazzini and Pedersen (2014). One of the most drastic contradictions to the theory above is momentum. This factor was originally based on the research of Jegadeesh (1990) and Jegadeesh and Titman (1993) and has been validated (out of sample) and studied by Grinblatt, Titman and Wermers (1994), Chan, Jegadeesh and Lakonishok (1996), Carhart (1997), Rouwenhorst (1998), Liew and Vassalou (1999), Moskowitz and Grinblatt (1999), Schiereck, De Bondt and Weber (1999), Hong, Lim and Stein (2000), Lee and Swaminathan (2000), Grundy and Martin (2001), Jegadeesh and Titman (2001), Okunev and White (2003), Cooper, Gutierrez and Hameed (2004), George and Hwang (2004), Moskowitz, Ooi and Pedersen (2010), Bandarchuk and Hilscher (2012), Novy-Marx (2012), Asness, Moskowitz and Pedersen (2013), and Daniel and Moskowitz (2016), among others.

In contrast to the mathematical factors of low volatility and momentum, the value effect has been integrated into the 3 -factor model of Fama based on original studies of Stattman (1980), Basu (1983), Rosenberg, Reid and Lanstein (1985), and Chan, Yasushi and Lakonishok (1991). These studies have demonstrated that the average returns are related to book-to-market value and earnings-price ratios. These studies were reaffirmed later, e.g., by Pontiff and Schall (1995) or Asness, Moskowitz and Pedersen (2013). Another value-related factor is the dividend yield, which was reported in Dhillon and Johnson (1994) and discussed in Charest (1978), and Fama and French (1988).

The list of factors that affect future asset returns is even longer and the situation is even more complex. Gupta and Kelly (2019) analyzed 65 well-known factors and showed that the factors can be combined via a momentum strategy generating even stronger abnormal returns than the factor combinations alone. It should be mentioned that this experiment is similar to the research of Haugen and Baker (1996), who assembled 60 fundamental and technical factors and showed how they can be tested monthly to derive abnormal returns.

In addition to this kind of 'factor zoo' (see Feng, Giglio and Xiu (2017)), there are two other main critiques regarding the assumptions of modern finance theory.

\subsection{Mathematical Analysis}

The basic assumption of the independence of asset returns has been questioned, e.g., in Taylor (1962), who used spectral analysis and the concept of price-trends to reject the hypothesis of an underlying random walk for asset prices. Similarly, Stevenson and Bear (1970) analyzed frequencies and serial correlations to reject the random walk model. Lo and McKinlay (1998) showed via a scaling argument (measuring volatility at different scales) that volatility does not scale in a way the underlying model intends and strongly reject a random walk model. Mandelbrot (1963) used a scaling argument for price increments to assume asset prices as 'Paretian'. Later, Mandelbrot and Van Ness (1968) were able to generalize geometric Brownian motions by using the Hurst exponent as a third statistical force (in addition to drift and volatility). However, they confessed that the deviations are slight and may not contradict the model of efficient markets. The work of Peters (1989) showed (using the R/S analysis of Mandelbrot) that stock markets and bond markets '[...] tend to trend in one direction - until some exogenous event occurs to change their bias.' (p.32)

\subsection{Behavioural Finance}

Whereas the mathematical critique centers around whether market prices follow random walks, the work of DeBondt and Thaler (1987), Shiller (2003), Kahneman (2011) and Thaler (2015) challenges the underlying assumption of rational investors, the mathematical analysis used in this work might be a stronger argument. As stated in the introduction scale does matter when discussing phenomenas, which is addressed by Campbell (2014) by discussing the fundamental disagreements in finance theory ' [...] the joint hypothesis problem in tests of market efficiency, which is as much an opportunity as a problem and patterns of short-and long-term predictability in asset returns.' 
(p.593)

\subsection{Outline of Work}

With respect to this brief summary, one must ask why major achievements in the history of finance are so diverse and contradictory. Why do different research teams answer a simple question such as 'Are markets efficient?' in completely different ways?

As we will argue in the following sections, this question is also a question of scale. Mandelbrot (1967) addressed the question of 'How Long is the Coast of Britain?' and introduced the concept of statistical self-similarity, which shows that the answer depends on the scale used for the measurement. We will use multi-scale techniques from wavelet theory (i.e., the Haar wavelet, the simplest form of a discrete wavelet transform) and show that log returns can be seen as coefficients of the lowest possible scale of that transform of the original data. Second, we use an explicit trend model based on a continuous wavelet transformation introduced by Berghorn (2015) to analyze trends. Reaffirming the work of Peters (1989) using R/S scaling analysis, we view markets to be fractal and inefficient in the long run and efficient in the short term. More specifically, we assume trend-based non-stationary processes of Berghorn and Otto (2017) and discuss how this view affects the core assumptions of Markowitz (1952). Consequently, we will discuss whether investors will potentially converge to efficient frontiers. We will extend original experiments by Berghorn and Otto (2017) and revisit the factors of momentum, low volatility, size, and value. We will argue that this subset of factors has a trend-based replication (a linear transfer function with some accuracy) and show that the resulting portfolios are similar to those produced by classical factor approaches in finance. We derive from these experiments why value and momentum are mathematically anti-correlated and why neither is correlated to low volatility - it is a matter of scale. We will also discuss why value strategies can be regarded as risk factors, whereas momentum and low volatility can be seen as trend factors. Concerning momentum, we will present a case study illustrating how these trends can occur, although markets seem to react efficiently on arriving information. We then use a return-based linear model of asset pricing and show that even a restricted set of factors, namely, momentum, value, and low volatility, has similar statistical power compared to the capital asset pricing model. Additionally, we view these factors as investor styles that generate excess returns in different market regimes, similar to Anderson and Noss (2013). Under this assumption, investors will not view asset characteristics for their portfolio decision homogeneously, as assumed by Sharpe (1964). Finally, we will review certain aspects discussed in the introduction from the viewpoint of (fractal) trend-based investor reactions and conclude that markets may be seen as asymptotically efficient once the role of scale has been clarified and incorporated into the model.

\section{Market Data, Definition of Factors, and Trending}

In subsequent chapters we will show that an explicit trend model (modelling upward und downward trends in end-of-day price data) can be used to describe factor behaviour (measuring e.g. the price-earning ratio or momentum). In brief this is done by selecting a trend model parametrisation which allows classical factors being described by a regression model with high accuracy. Our simulation results are based on the combined market S\&P 500 and STOXX 600 constituted at May 10th 2019. Data provider is Bloomberg. Because this research is focused on the characteristics of time series data, we do not compensate for any index changes. We construct a value weighted market proxy as used in Berghorn (2015). This construction design is equivalent to the one used to constitute the DowJones Index, and it serves as a market proxy in the remainder of this work. The dataset itself contains 1,105 assets combining large cap US and European stocks. The period used for the analysis is the beginning of 2004 through the end of 2018 (15 years). Any asset that has been integrated into the index after 2018 is excluded. The resulting set of assets comprises 1,100 companies.

We will apply factors to this dataset, i.e., we will measure certain characteristics (either trend characteristics, historical price performance or fundamentals) over some past periods on a monthly basis. Classical factor calculations comprise momentum, low volatility, price ebitda ratio, dividend yield, and price book ratio.

For the price data, we will use end-of-day data. Monthly, we will sort the measured characteristics using Z-scores (Note 1) and pick the top/bottom fraction of assets to establish a portfolio. To simulate realistic portfolios, we also subtract $0.1 \%$ of the whole volume to anticipate trading costs on a monthly basis. To harmonize with Berghorn et al (2021), we will use $10 \%$ deciles, i.e., 110 out of 1,100 assets, to evaluate the factor performance.

We do not discuss in detail the statistics of the performance curves for individual factors and refer the reader to the literature mentioned in the references at the end of the paper. We report only key characteristics such as the drift of daily returns, the volatility of daily returns, and the ratio of both, i.e., the daily risk-adjusted returns and the maximal drawdown seen in the experiments. 
In some examples, we will use random processes, namely, geometric and fractional Brownian motions. We estimate the drift, the volatility, and the Hurst exponent (by using the R/S analysis). For the sake of completeness and as Figure 1 shows, 977 of 1,006 assets (including the proxy value weighted market index) used in this work exhibit Hurst exponents greater than 0.5. This signals that trending in asset price series (or long term memory) is widely present as (as modelled by fractional Brownian motions).

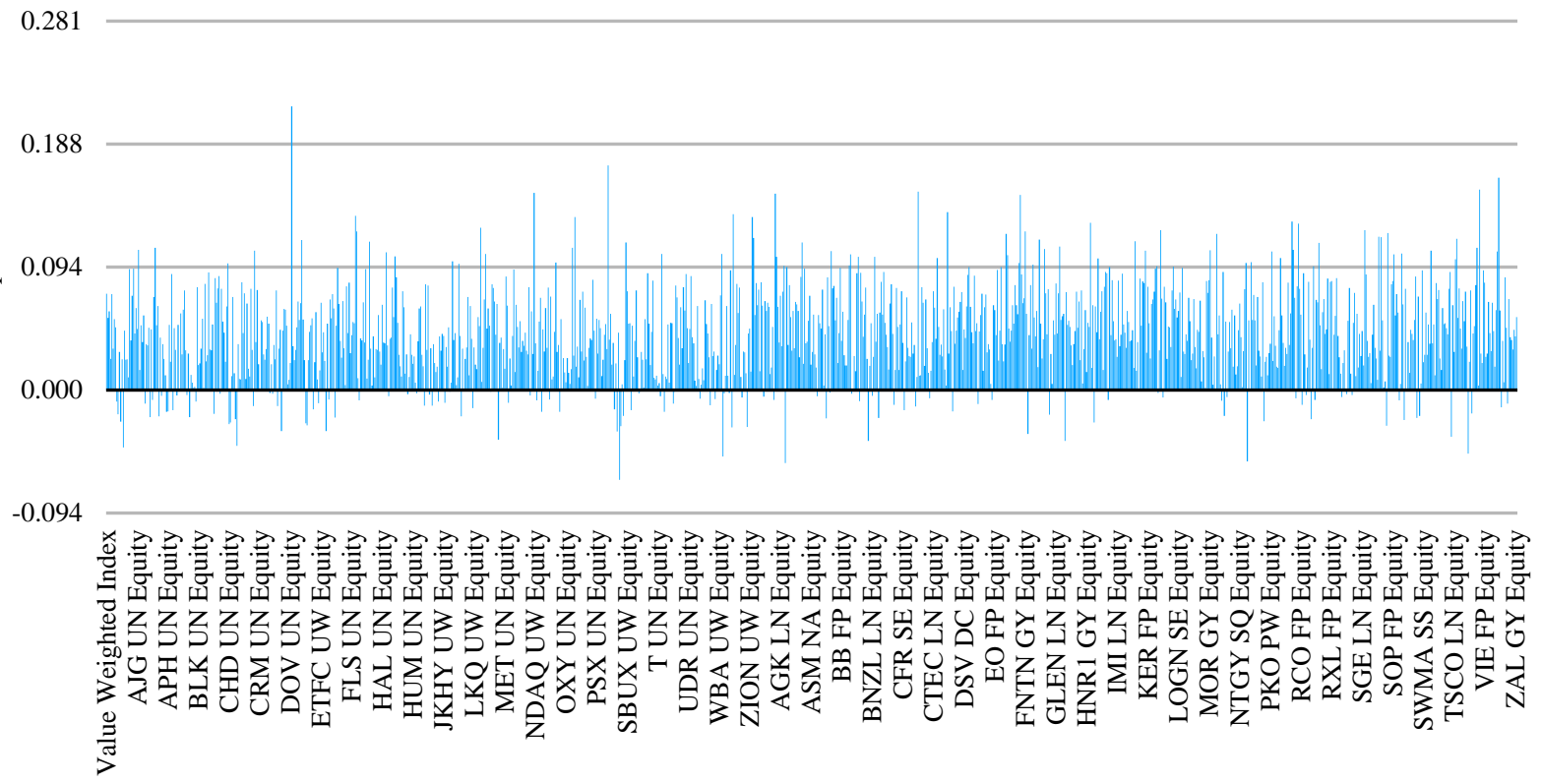

Asset

Figure 1. Hurst exponents - 0,5 per asset

\section{Wavelets, Trends, and Random Walks}

With the research in wavelet theory at the end of the last century (for an introduction, we refer to Louis, Maaß and Rieder (1994)), Ramsey, Usikov and Zaslavsky (1995), Ramsey (1999), and Ramsey (2002) used a new technology to examine the question of whether stock market data follow a random walk. Analyzing the U.S. stock market, Ramsey, Usikov and Zaslavsky (1995) found that ' [...] there seems to be some evidence of non-randomness in the data' (p. 377), which can be related to the most simplistic form of a wavelet transform, the Haar transform. In the discrete case, wavelet theory is based on smoothing (averaging) data and collecting the missing details (in case of the Haar wavelet, it is the difference in adjacent data points) to preserve the information of a signal and reversibility.

Let us assume that we have discrete end-of-day stock market data $S_{i} \in \mathbb{R}^{+}$for $i=1, \ldots, n$ with $n \in \mathbb{N}$ and $n>1$. Then, formally, the first step (on scale 1) of that discrete (and dyadic) transform is to calculate the smooth part of the data by calculating

$$
S_{k}=\frac{\tilde{S_{2 k+1}+S_{2 k}}}{\sqrt{2}} \text {, where } k=\left\lfloor\frac{n}{2}\right\rfloor
$$

In the second step, the details $d_{k}$ are collected using

$$
d_{k}=\frac{S_{2 k+1}-S_{2 k}}{\sqrt{2}}
$$

As such, the calculation is subsampling the data (taking adjacent pairs of original values). If we use the natural

logarithm on our original data $\tilde{S_{i}^{\ln }}:=\ln \left(\tilde{S_{i}}\right)$, this transform reflects a scaled and subsampled version of continuous returns. The smooth part $s_{k}$ is now recursively treated by the formulas above. Every step coarsens the data at dyadic 
wavelet scales $1,2,4, \ldots$. As such, the coefficients $s_{k}$ and $d_{k}$ are using $2,4,8, \ldots$ data points and can be interpreted as longer-term returns.

From this perspective, it is already clear why the open question of whether data can be represented by a random walk model is answered so differently. Fama (1995) used a short-term view (essentially at wavelet scale 1), where Taylor (1962) used broader scales.

\subsection{Fractal Processes and Trends}

In the following section, we will focus on the question 'are geometric Brownian motion and the generalization, the fractional Brownian motion, adequate models for representing stock market data'? To answer this question, we will use an explicit trend model introduced in Berghorn (2015). Shifting now from the discrete notation $S_{k}$ for asset prices, we use $S_{k}$ as a continuous function for price records of asset $k$. When we refer to an individual stock, we will use the notation $S_{k}$, where $k$ runs from $1, \ldots 1110$.

The continuous wavelet transform $W_{\psi} S$ is defined as a convolution of a signal $S(t)$ with a convolution kernel $\psi$

$$
\mathrm{W}_{\psi} \mathrm{S}(\mathrm{a}, \mathrm{b})=\frac{1}{\mathrm{a}} \int_{-\infty}^{+\infty} \overline{\Psi\left(\frac{\mathrm{t}-\mathrm{b}}{\mathrm{a}}\right)} \mathrm{S}(\mathrm{t}) \mathrm{dt}
$$

for some admissible wavelets $\psi$ and a wavelet scale $a$ at location $b$. Rooted in the generalized Heisenberg uncertainty principle (Note 2), we choose the first derivative of the Gaussian function (which is then a wavelet). Consequently, the convolution has the most precise localization properties in frequency and time. If $\psi$ is differentiable, it follows that $W_{\psi} S(a, b)$ is also differentiable, and we are able to determine local extrema $M$. The first derivative of such a smoothing process is similar to the Haar transform, i.e., the Haar transform calculating differences $d_{k}$ can be viewed as a scaled approximation to a first derivative. Return measurements, such as those used in momentum strategies, can consequently be seen as coarse approximation to a first derivative. In Berghorn and Otto (2017), a mathematical notation for a trend model is given. Essentially, between local extrema (under smoothing), linear trend segments are assumed. Formally, applying a wavelet transform $W_{\psi}$ with a "smooth" wavelet $\psi$ (being differentiable) to an asset with prices $S$, we can apply an operator (see Berghorn (2015))

$$
V_{\psi}(a, S): S \rightarrow M(a, S)
$$

where we assign a given price record $S$ the observed extrema under smoothing at wavelet scale $a$. We drop at this point the notation $\psi$, as we will exclusively use the Gaussian function. $M(a, S)$ can be seen as a set of indices

$$
M(a, S)=\left\{m_{1}^{a}(S), \ldots, m_{m}^{a}(S)\right\},
$$

where $m_{l}^{a}(S)$ is pointing to the location of the $l$-th extreme value under smoothing (see Evertsz (1998)).

We now switch back to a discrete form and take the last observed local extrema under smoothing $m_{m}^{a}(\tilde{S})$ for a discrete signal $S$ and estimate for the $k$-th trend the size by

$$
C_{k}^{\text {size }}(M(a, S)):=m_{k+1}^{a}(S)-m_{k}^{a}(S) .
$$

We can estimate a generalized trend drift $\mu$ using continuous returns $r_{i}=\ln \left(S_{i}\right)-\ln \left(S_{i-1}\right)$ :

$$
C_{k}^{\mu}(M(a, \tilde{S})):=\operatorname{sign}(a) \frac{1}{m_{k+1}^{a}(\tilde{S})-m_{k}^{a}(\tilde{S})} \sum_{l=m_{k}^{a}(\tilde{S})}^{m_{k+1}^{a}(\tilde{S})} r_{l}
$$

$C_{k}^{\mu}(M(a, \tilde{S}))$ is generalized in the sense of allowing estimates of negative trends given a wavelet scale $a$. Using a

single trend segment only, we can define the trend volatility in a similar way.

We now view the market as an aggregate. For the following experiment, we calculate for a given wavelet scale $a$ and an asset $S_{k}(t)$ the linear trend model and measure the trend sizes seen historically. We aggregate the market by collecting all trend sizes of all individual assets $S_{k}(t)$ for a given wavelet scale $a$ and report averages in business days. This procedure is finally compared with two models, the fractional and geometric Brownian motion, using the historically estimated drift, volatility, and the Hurst exponent (using an R/S analysis) for each individual asset of a market. We generate 1,000 realizations for every asset, calculate the trend sizes of these models and average the trend sizes observed per scale over all asset realizations. The resulting average trend sizes per scale show that market data has longer trends (see Figure 2) and a higher standard deviation (both measured in business days) when compared to the fractional and geometric Brownian motions (see Figure 3) (Note 3). From the trend model perspective, both 
random processes can be viewed as similar (they are almost identical when the average trend sizes are compared).

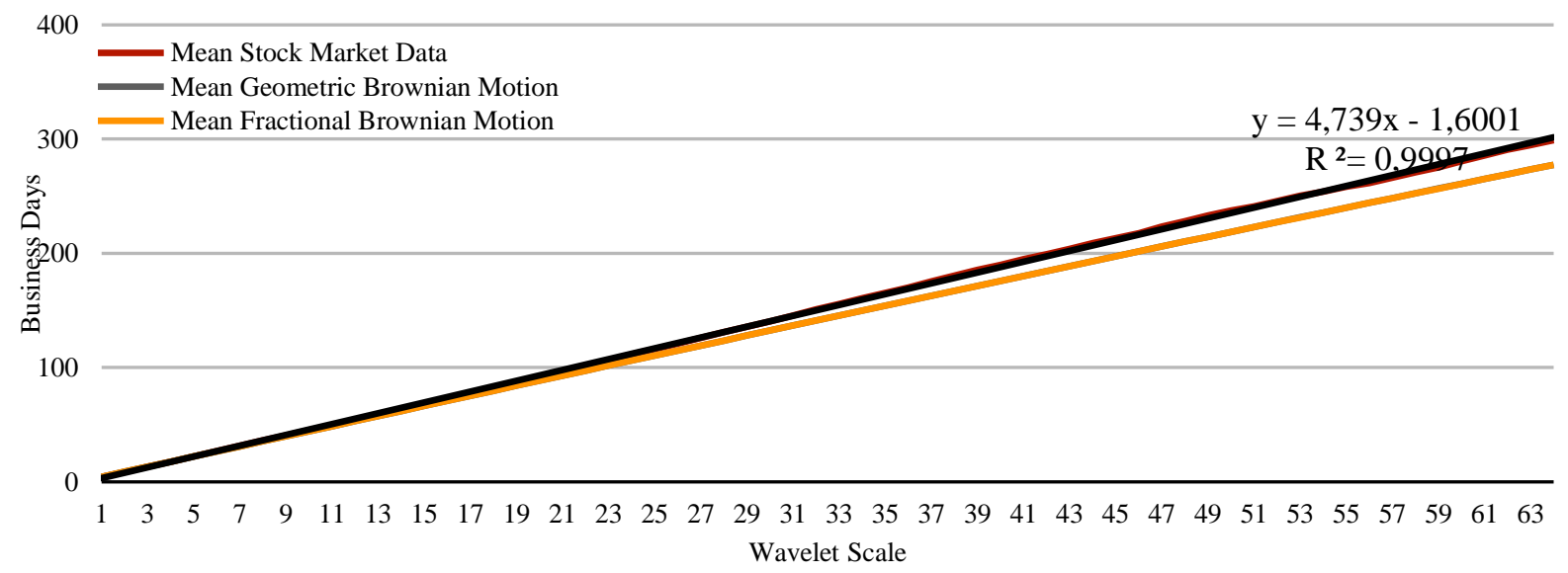

Figure 2. Averages of trend sizes seen (Random Walk vs. Stock Market Data)

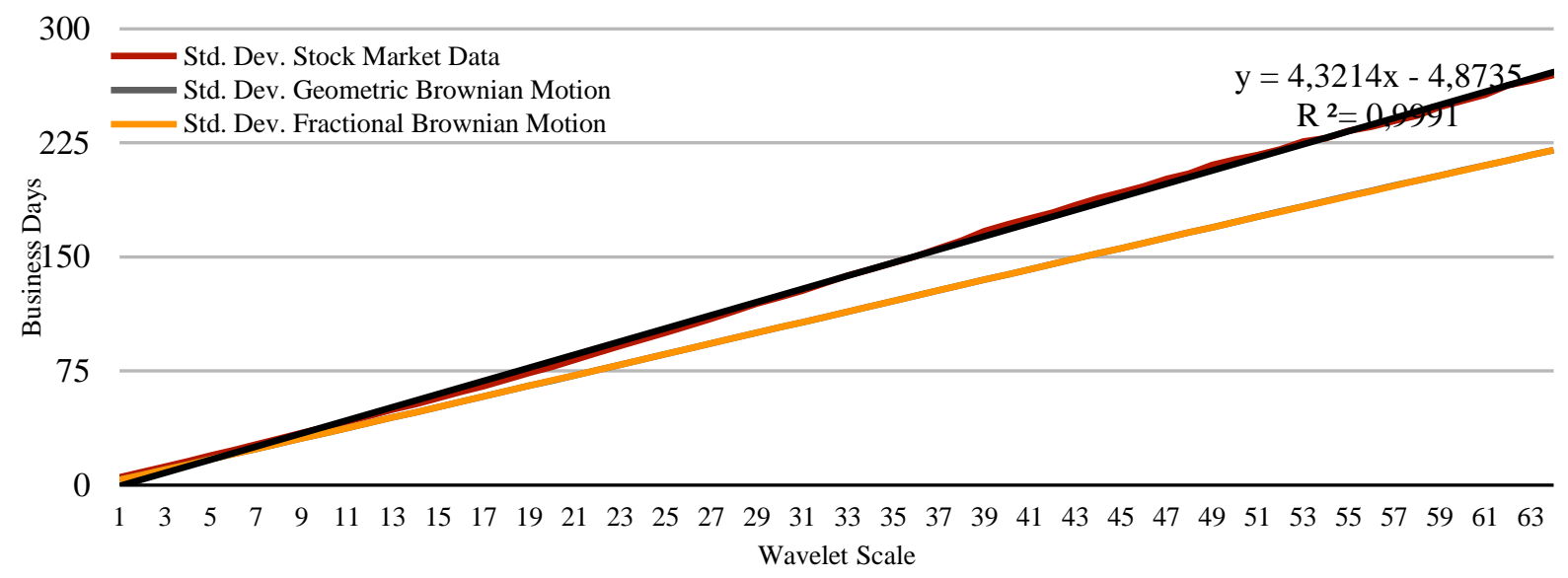

Figure 3. Standard deviation of trend sizes seen (Random Walk vs. Stock Market Data)

As seen above, trends in assets (as an aggregate) follow a linear relationship to business days. With higher scales $a$, the difference in trend sizes between models and real data increases. For example, if one chooses a coarse scale, e.g., $a=64$, one finds that trends are already approximately 21 business days longer in aggregate than realizations of fractional and geometric Brownian motions, which potentially allows a monthly re-balancing (assuming 21 business days per month). However, the statistical analysis also shows that the width of the distributions is fundamentally different. As shown in Berghorn (2015), individual assets exhibit drastic trend characteristics that cannot be modeled by the geometric Brownian motion, which is similar to Mandelbrot's view, who expressed that market data are "wilder" with respect to outliers than normal distribution can provide.

\subsection{Wild Trends: An Example}

We now consider assets that have a history of price records for more than 5 years (Note 4 ). We decompose all assets into trends and calculate the trend sizes at scale 23. Finally, we select the 100 longest trends seen and sort the assets according to their trend sizes (see Figure 4). 


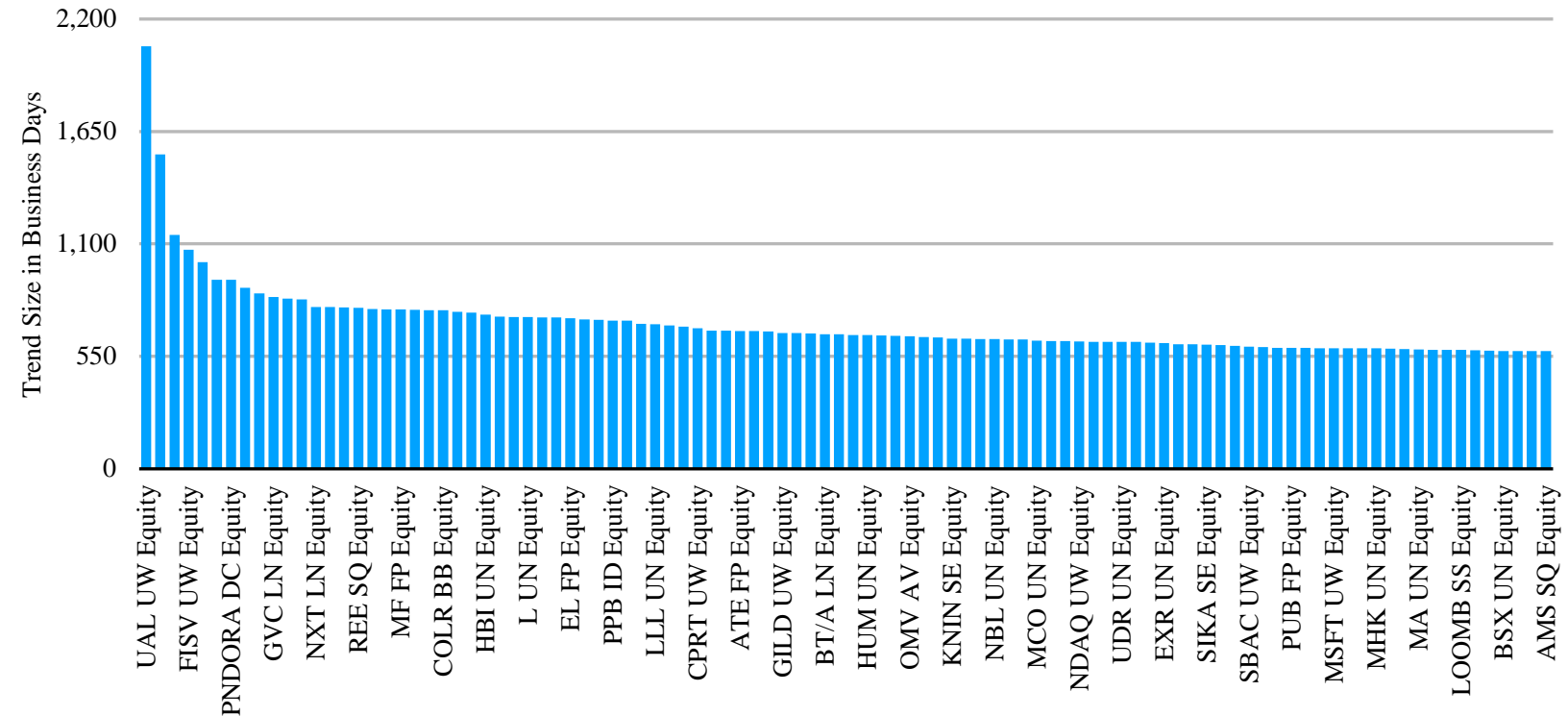

Asset

Figure 4. "Wild" trends: 100 longest trend sizes at Wavelet Scale 23

Using 10,000 random walk realizations, we determine the trends of these realizations at scale 23 and analyze how often we would see such a situation under a model using the estimated drift and volatility of the individual assets. The answer shows that this situation is rare: $95 \%$ of assets have a random walk representation, which has a probability close to zero to render such long trends.

\subsection{Discussion}

In aggregate, for small scales $a$, the deviations between trend sizes seen in the market and random walk realizations "converge" to zero. In that regard, fractional Brownian motion modeled by Mandelbrot represents inefficient markets (if scale $a$ is coarse enough); however, it is still not sufficient because market data exhibit even longer trends. In Berghorn and Otto (2017), a fractal, trend-based (and therefore non-stationary) model is chosen to determine whether momentum markets can be generated.

From a theoretical point of view, there are important consequences, as in non-stationary, fractal markets, some key assumptions of Markowitz (1952) are not fulfilled: two investors estimating expected returns as well as the associated covariances using different time horizons will obtain different estimates. There is another theoretical argument that can be made in conjunction with the central limit theorem. The Haar transform illustrated above is reversible. Let $f$ be a reconstruction coefficient applying the inverse of the Haar transform

$$
f_{2 k}=\frac{s_{k}-d_{k}}{\sqrt{2}} \text { and } f_{2 k+1}=\frac{s_{k}+d_{k}}{\sqrt{2}}
$$

using the coefficients $s_{k}$ and $d_{k}$ from (1) und (2). Under the assumption that $s_{k}$ and $d_{k}$ (on all levels of that transform) are independent variables, the recursive back transformation to obtain $f_{k}$ would follow the central limit theorem because independent random variables are added. This argument chain follows the reasoning of Rice (1995). In other words, trend structures are difficult to see when multi-scale approaches are not involved.

It is also noteworthy to mention that statistical tests are a very 'coarse' view. As shown in Berghorn and Otto (2018), trend sizes might stem from a lognormal distribution.

\section{Factors}

Gupta (2019) observed 65 different factors from the literature on a monthly basis (using the previous month's performance) to create a portfolio of outperforming factors in the following month.

In our view, this approach is similar to the work of Haugen and Baker (1996), who examined 60 factors (fundamental 
and technical ones) and estimated the slopes (betas) of a linear regression between the market and the relevant factors over a period of one year. In the second step of that work, a return estimate for all factors and for all individual assets was calculated by using these betas multiplied by the ranking of an asset. These return estimates were finally ranked and used for an investment decision.

From a high-level perspective, it can be considered that both studies address the well-known fact from literature that factors (e.g., momentum or value) have long underperformance periods. Furthermore, these approaches again confirm the strong anti-correlation between the momentum and value effect.

The reasoning why the approaches in Haugen and Baker (1996) and Gupta (2019) work is given in the following experiment.

\subsection{Factor Trending}

Let us assume that we have continuous stock market records $S_{k}(t)$. We can now measure the return at some scale $a \in \mathbb{Z} \backslash\{0\}$ with

$$
R\left(a, S_{k}, t\right)=\operatorname{sign}(a) \frac{S_{k}(t)-S_{k}(t-|a|)}{S_{k}(t-|a|)}
$$

We explicitly allow negative scales that can be interpreted as an anti-momentum measurement because assets with negative past returns are ranked higher.

Let us assume that we allow double sorting via Z-scoring. In other words, we combine two measurements $R\left(a_{1}, S_{k}, t\right)$ and $R\left(a_{2}, S_{k}, t\right)$, normalize for all measurements $i$ seen in the market by Z-scoring, and finally add both normalized measurements. In the following experiment, we choose for each following month the best generalized momentum combination of two scales $a_{1}$ and $a_{2}$, where scales $a_{1}$ and $a_{2}$ vary from -72 months to +72 months. Every generic factor is executed with only 30 assets, and the factor performance from a previous month determines the factor used in the following month. This technique of using 1-month-momentum to generalized momentum strategy exhibits momentum characteristics, as shown in Figure 5.

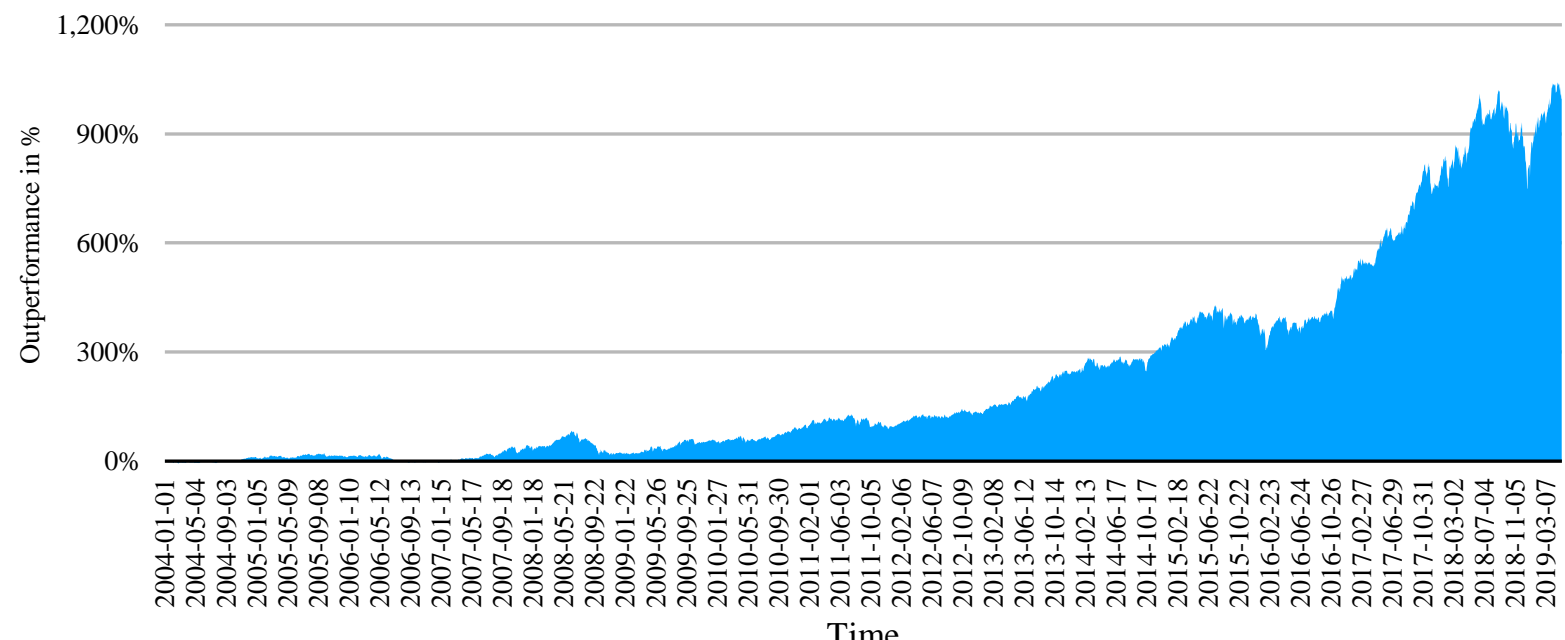

Figure 5. Momentum of generalized momentum (30 assets)

This generalized momentum approach supports the viewpoint of Haugen and Baker (1996) and Gupta (2019), but does not use any fundamental data or economic data. It is based solely on the past performance characteristics of assets. Thus, the price development of assets is not independent from the past and allows timing.

\subsection{Trends and Factors}

In the following section, we consider the regression model

$$
R_{F_{i}}(t)=\alpha_{i}+\beta_{i} R_{T_{\mathbb{A}} d}(t)+\epsilon_{i, t},
$$

where $R_{F_{i}}(t)$ represents the daily return of a classical factor $F_{i}$ (such as momentum). We regress the logarithmic 
daily returns of a trend replication $R_{T_{\mathrm{A}^{d}}}$ given a set of scales with varying dimensions $d$. As such, we use the notation $\mathbb{A}^{d}$, where $\mathbb{A}$ is a generic set of scales. For example, in the three-dimensional case, we use

$$
\mathbb{A}^{3}=\{\{-128, \ldots, 128\} \times\{-128, \ldots, 128\} \times\{-128, \ldots, 128\}\} .
$$

The boundaries are chosen to limit the optimization process. Please note that we use for different factors $F_{i}$ different dimensions $d$.

We then measure the coefficient of determination $R^{2}$ and determine the optimal scale $a \in \mathbb{A}^{d}$ so that $R^{2}$ is (sub-) optimal. In essence, we would like to identify scales $a \in \mathbb{A}^{d}$ that best explain the factor $F_{i}$ under consideration.

In the regressions, we use momentum, low volatility, value strategies and the size effect. Each experiment reports key strategy characteristics such as daily drift, daily volatility, daily risk-adjusted return, and maximum drawdown.

In the case of a higher number of scales, this replication approach involves heavy computational efforts. Therefore, we use the pattern search approach developed by Hooke and Jeeves (1961), which may come close to global optima. To verify whether the outcome of this optimization is artificial, we extend these experiments by measuring the portfolio distance between the original factor and the wavelet trend-based replication. To remain consistent with later sections, we will now assume decile portfolios, i.e., we consider 110 assets in the monthly ranking.

\subsubsection{Portfolio Distance}

Let us assume that we have 1,100 assets, and rank monthly assets according to a factor $\Gamma$, i.e. we map a stock $S_{k}$ to

$$
\Gamma: S_{k} \rightarrow \gamma \text { at some timepoint } t \text {. }
$$

The resulting portfolio has a sorting of assets $A_{\Gamma\left(s_{1}, t\right)}, \ldots, A_{\Gamma\left(s_{n}, t\right)}$ at time $t$. We repeat our study with a factor $\Gamma^{\prime}$ and obtain a different ranking $A_{\Gamma^{\prime}\left(s_{1}, t\right)}, \ldots, A_{\Gamma^{\prime}\left(s_{n}, t\right)}$. Under the assumption, that we use only 110 of the top-ranked assets, i.e. the $10 \%$ decile, we then compute the distance of a portfolio position by applying $\Gamma$ and $\Gamma^{\prime}$ and normalize this with the maximal possible distance of portfolio $D_{\max }$

$$
D\left(\Gamma, \Gamma^{\prime}, S, t\right)=\frac{\left|A_{\Gamma(S, t)}-A_{\Gamma^{\prime}(S, t)}\right|}{D_{\max }}
$$

with

$$
D_{\max }=(1,100-1)+(1,099-2)+\cdots+(1,100-109-110) .
$$

In the following, we briefly discuss the main findings for each factor and summarize the results in one table. Therein we use for almost every factor the trend $\operatorname{drift}\left(C_{k}^{\mu}\left(M_{\text {last }}(a, S)\right)\right.$ of the last visible trend seen at a scale $a$ for the monthly ranking. In particular, we decompose every asset into trends given a wavelet scale $a$ and estimate the daily drift on the last trend segment visible. This trend drift is then used for the ranking of the monthly rebalancing.

\subsubsection{Momentum 6M and Momentum 12M}

We first address the momentum strategy based on the historic performance of assets measured over 6 months. Figure 6 illustrates the linear relationship (by using model of equation (10)) of the momentum strategy to a trend model. In particular we can find a linear regression model which describes the linear relationship of the classical factor end the trend model based factor, where assets are ranked based on the last visible trend at scale 23 using the trend drift. The risk-adjusted return of the original momentum factor is 0.0492 vs. 0.0434 of the replication. 


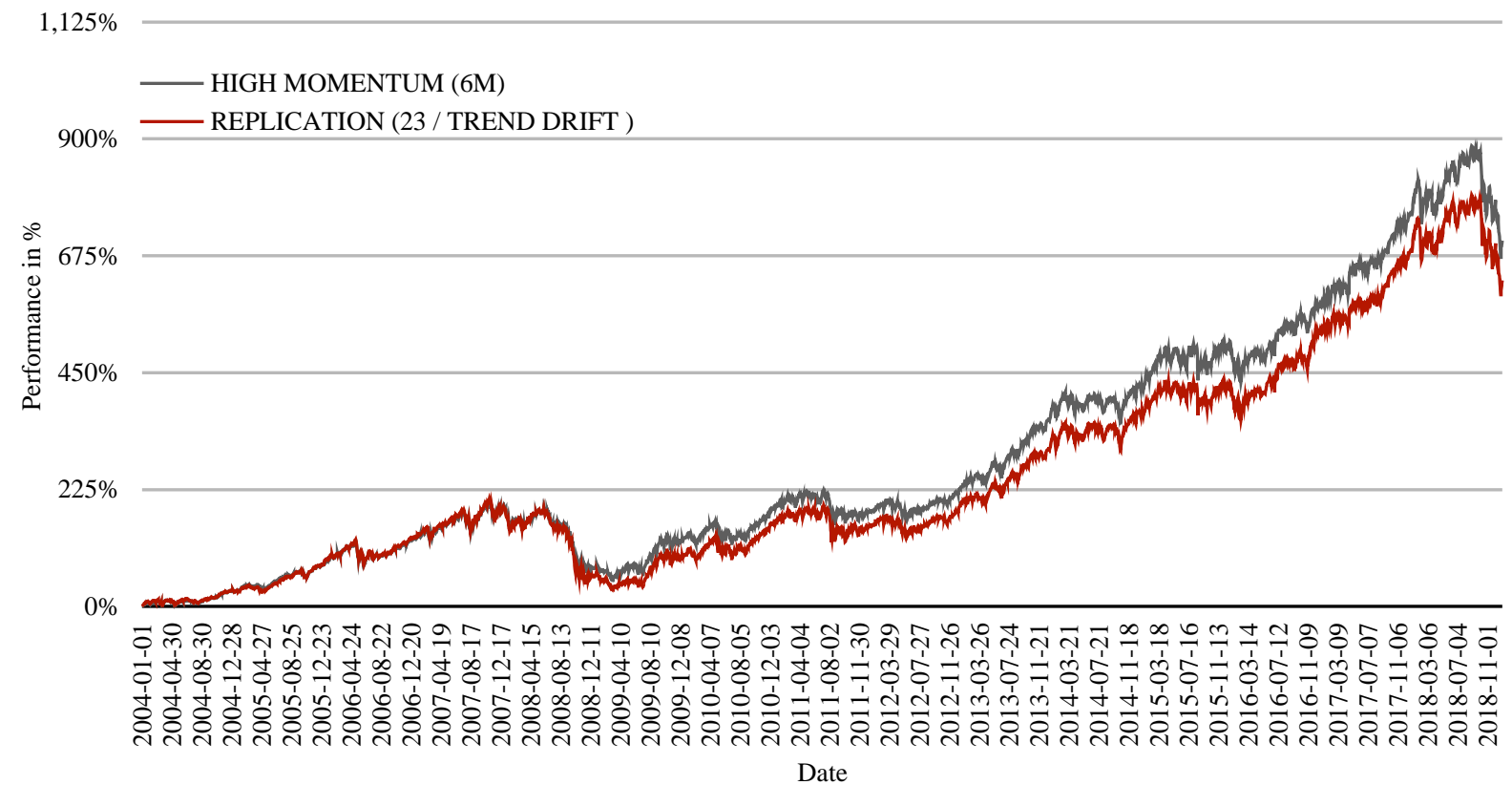

Figure 6. Replication of higher momentum decile (6M) using 110 assets

For longer time horizons (e.g., 12 months used for the asset rankings), we also deduce coarser scales, i.e. assets are ranked based on the last visible trend at scale 41 using the trend drift (see Figure 7).

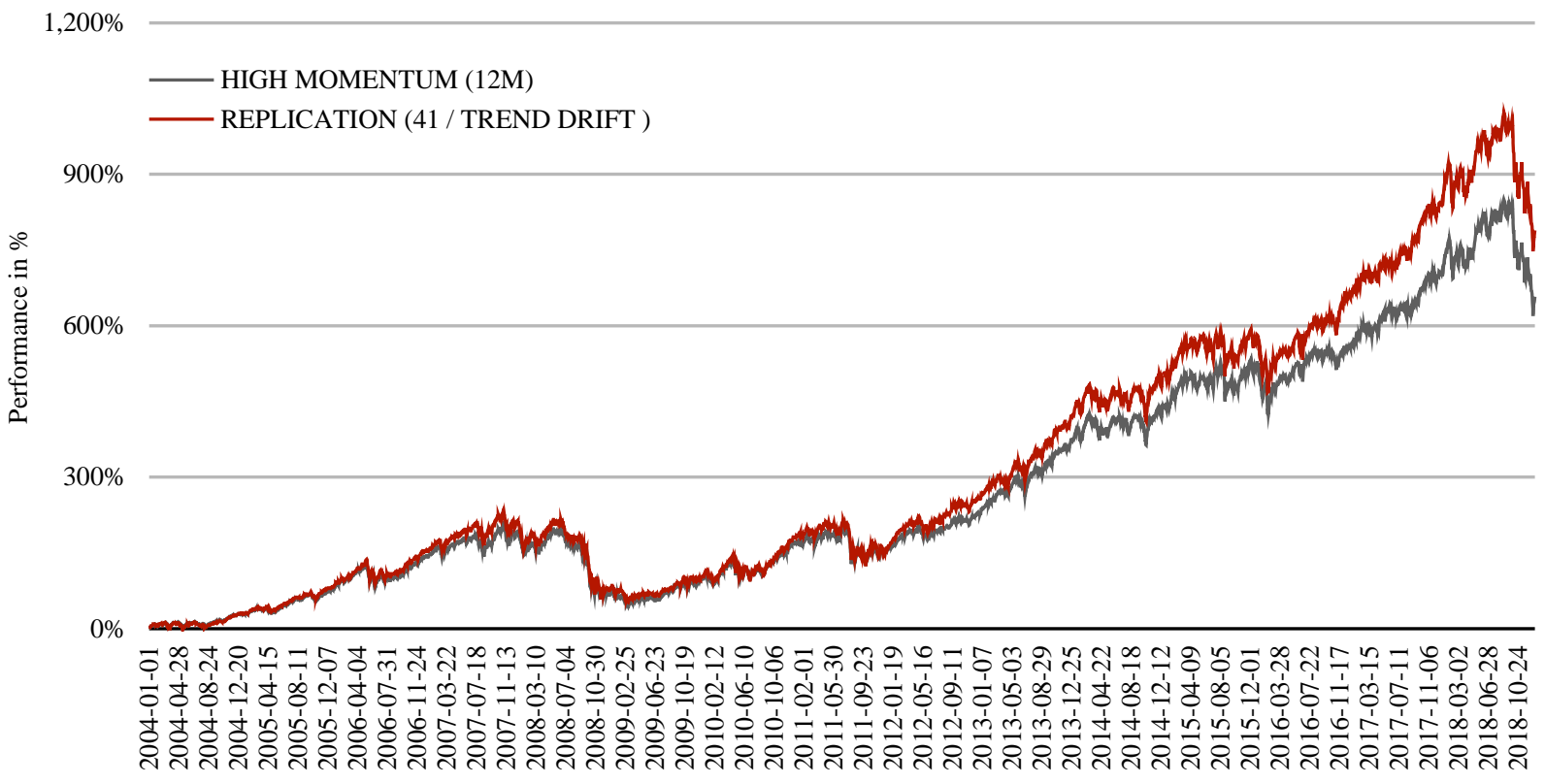

Date

Figure 7. Replication of higher momentum decile (12M) using 110 assets 


\subsubsection{Low Volatility}

According to Berghorn and Otto (2018) and Berghorn et al (2021), the low volatility factor is a side of the same coin when compared to momentum. It has been shown that the volatility of returns of the last trend seen under smoothing with scale $a$ generates similar performance characteristics compared to the original factor. For the classical factor of low volatility, we estimate monthly the volatility of the past three years (36 months) of every individual asset. Using the linear model fit from above, we obtain scale 89. Figure 8 shows the linear relationship of the low volatility factor to a trend model, where assets are ranked based on the last visible trend at scale 89 using an inverse volatility estimate.

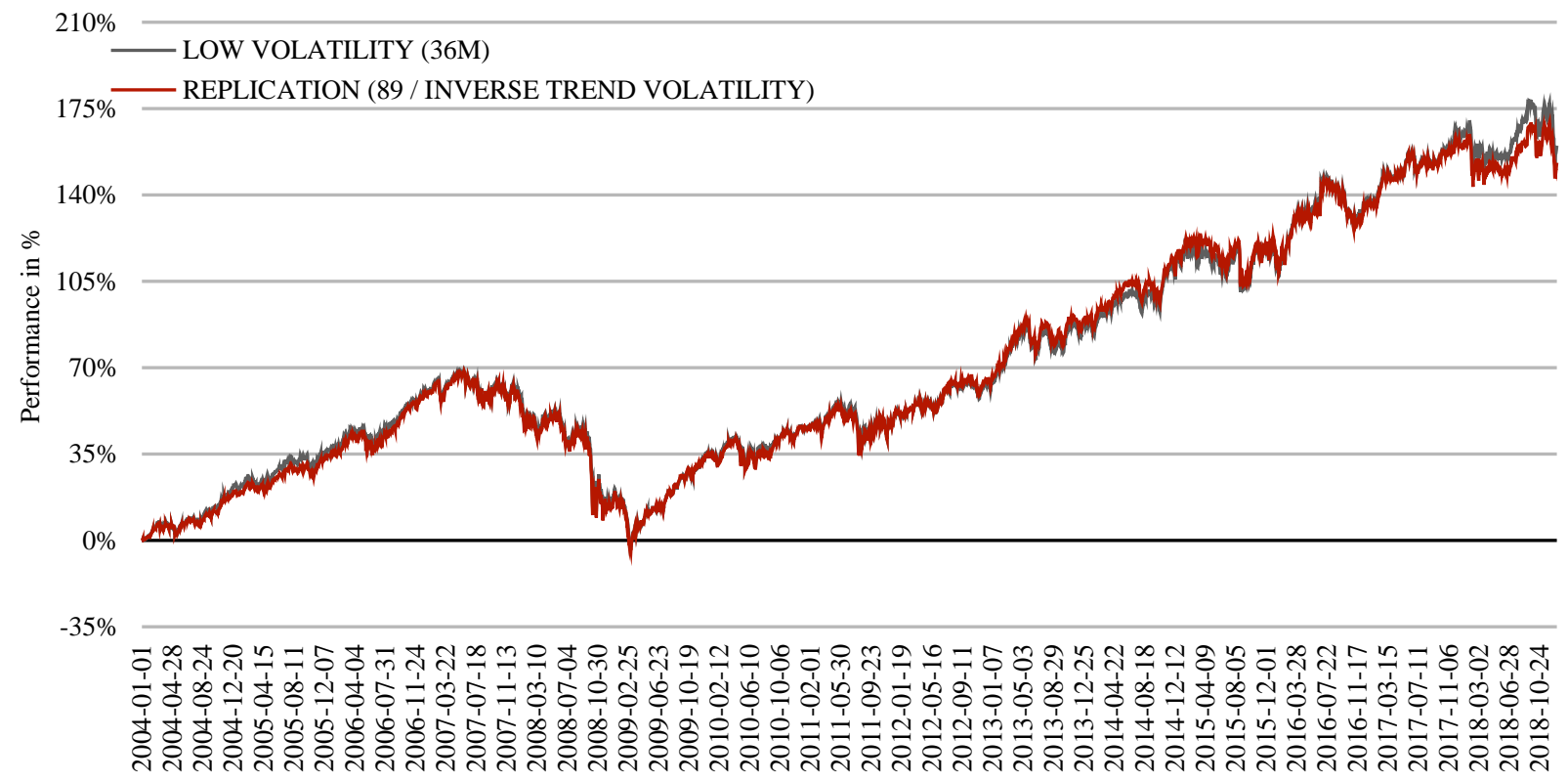

Date

Figure 8. Replication of low volatility decile (36M) using 110 assets

As defined in equation (9) above, we use a very generic concept of scale, i.e. we allow positiv scales as used above, but also negative ones. In the latter case we simply revert the ranking order by multiplying -1 to the computed trend characteristics (e.g. trend drift). This is being used in the following sections, where we focus on value strategies. As such, one can assume that negative scales will play an important role because an asset in a distress period will show up as more attractive when balance sheet data are combined with price data. Therefore, we use the pattern search approach for higher-dimensional scales.

\subsubsection{Value - Strategy 1: Low Price-to-EBITDA Ratio}

We evaluate the EBITDA and determine the $10 \%$ decile of assets with the lowest ratio of price and EBITDA on a monthly basis. Similar to the factors above, we are able to determine a trend-based strategy with high precision (see figure 9). The corresponding scales are 58, -128 and -39 and are partly negative. For all three scales, we will use the last visible trend and measure the daily drift on that segment. The measurements will then be combined using Z-scoring. 


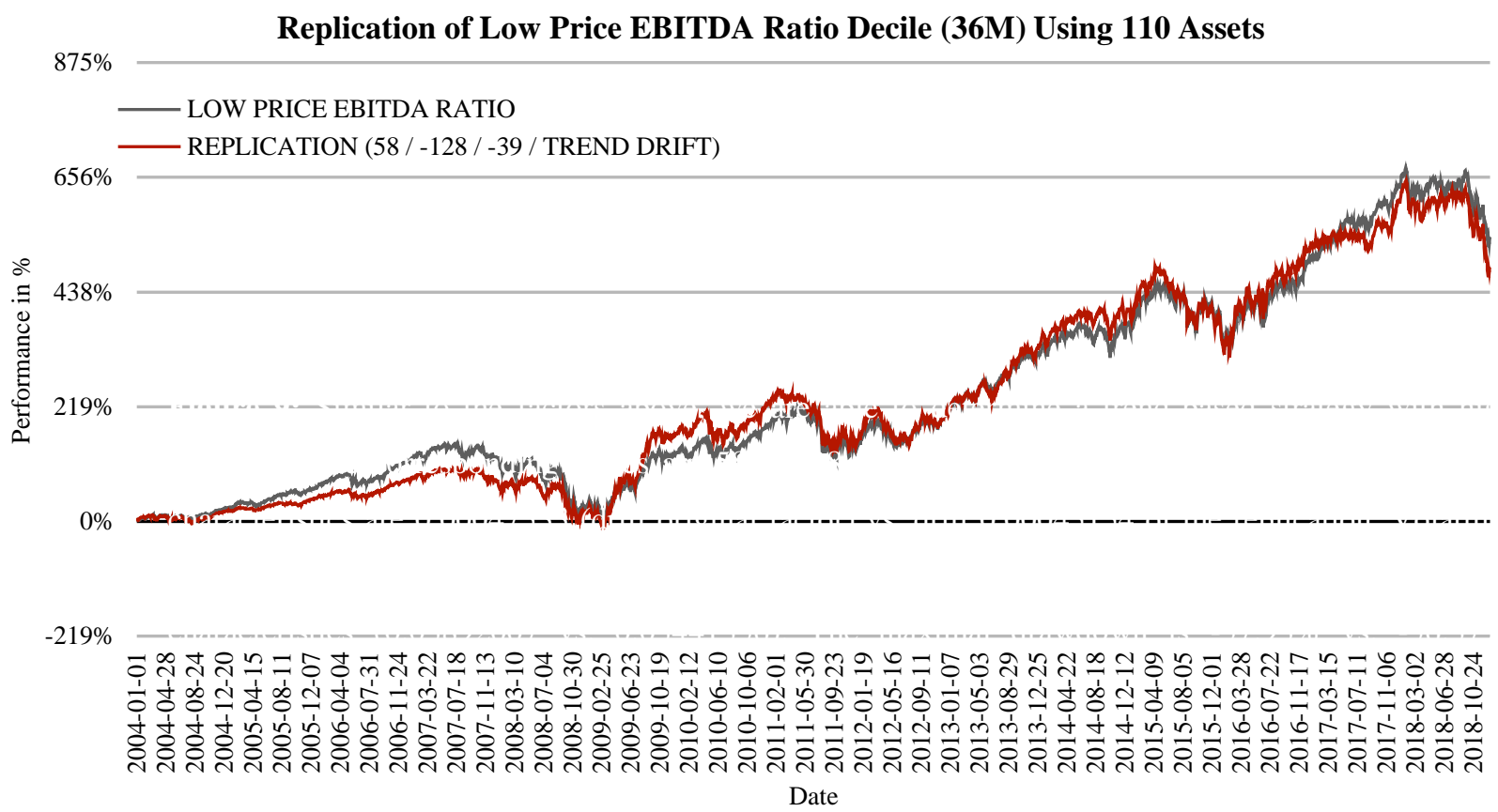

Figure 9. Replication of low price EBITDA ratio decile (36M) using 110 assets

\subsubsection{Value Strategy 2: Dividend Yield}

Similar to the fundamental ratio of chapter 4.2.3.1, we analyze a dividend yield strategy next. For every asset, we determine monthly the last paid dividend (reported in the balance sheet on a quarterly basis) and divide this number by the current share price. The corresponding scales in this experiment are 10 and -10 and the resulting performance chart is depicted in Figure 10.

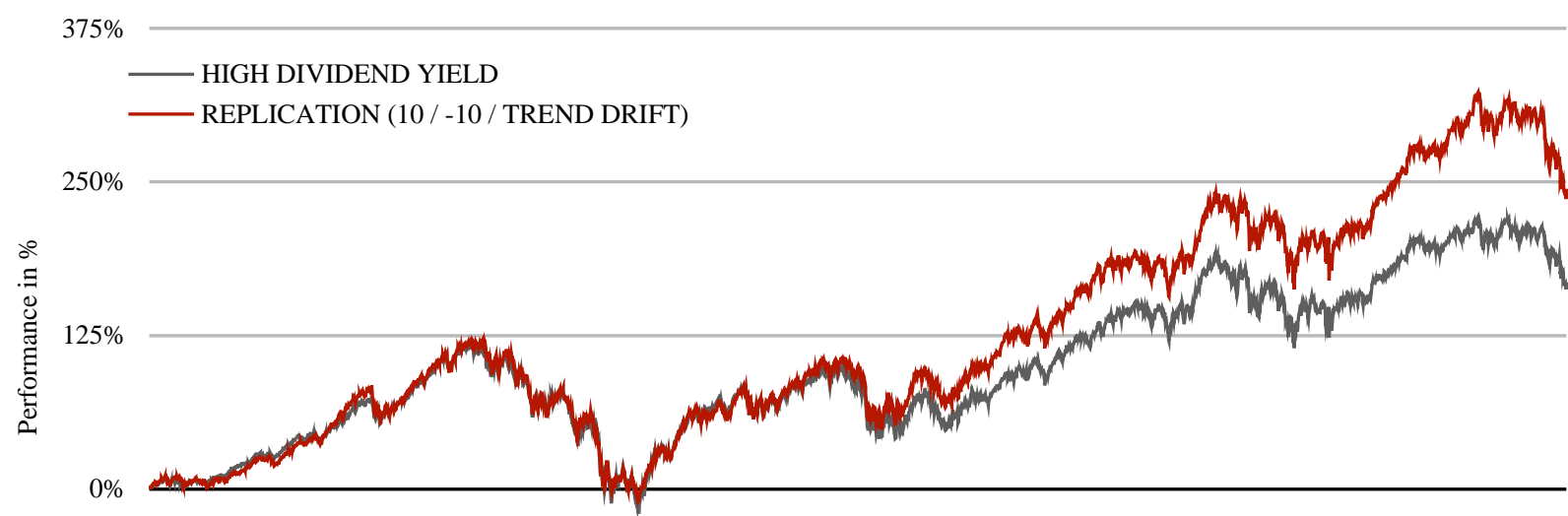

$-125 \%$

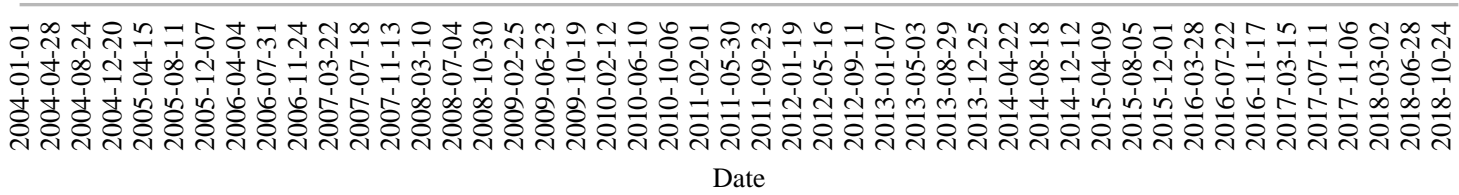

Figure 10. Replication of higher dividend yield decile (36M) using 110 assets 


\subsubsection{Value Strategy 3: Low Book-to-Market Ratio}

For value-based strategies, we now turn to the book-to-market ratio. This is a classical factor that is perceived as a risk factor and has been added to the 3-factor model of Fama and French (1992). In contrast to the value-driven strategies above, we find two negative scales (-93 and -97), as depicted in Figure 11.

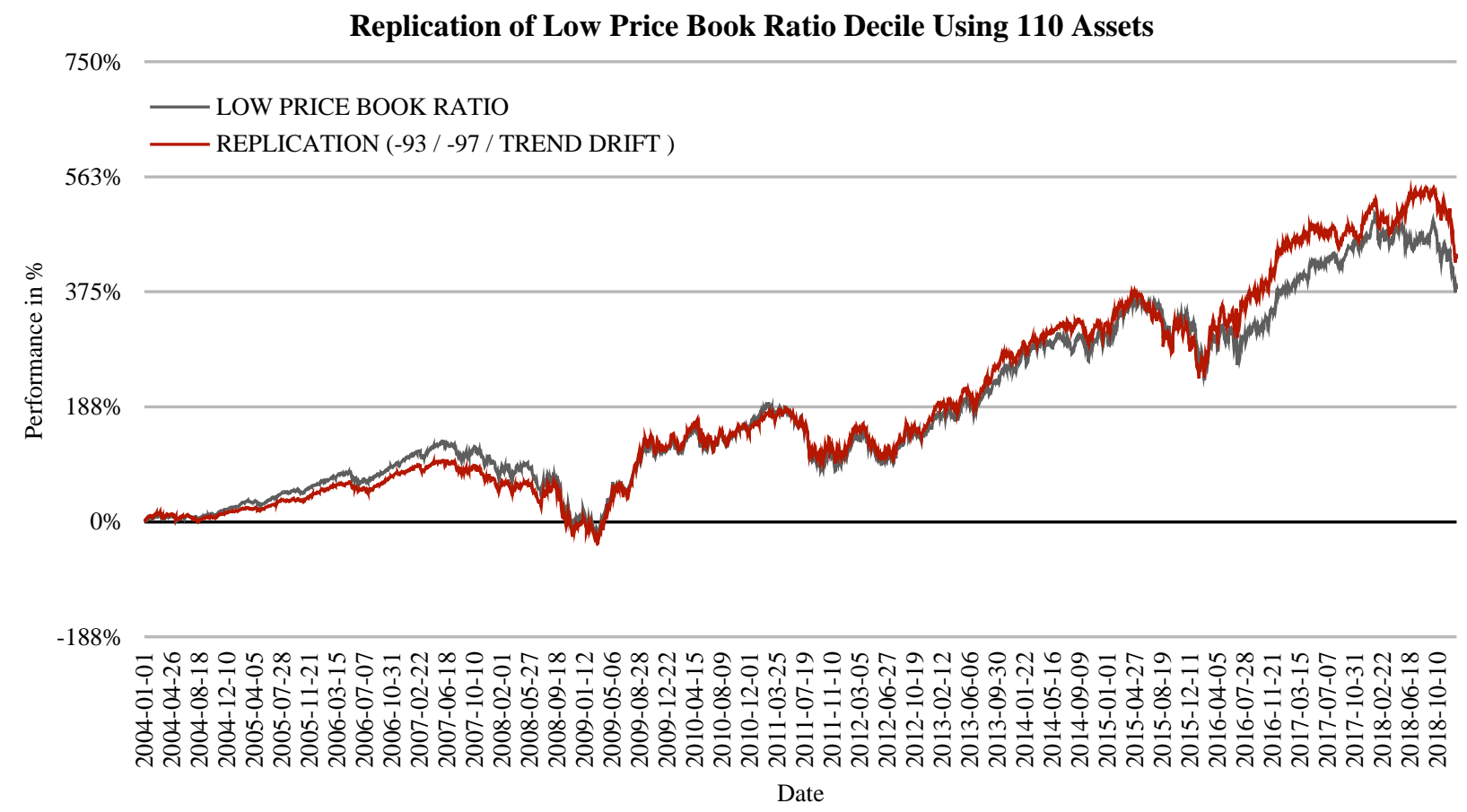

Figure 11. Replication of low price book ration decile using 110 assets

\subsubsection{Size}

In the 3-factor model of Fama and French (1992), the size factor as well as the value factor are established as risk-based factors. A possible implementation of the size factor is equally weighting the portfolio on a monthly basis using 1,100 assets. Assets are ranked based on the last visible trend drift at scales (127 and -110) using Z-scoring. Figure 12 shows how this weighting can be replicated by a fraction of $10 \%$ of all assets: 


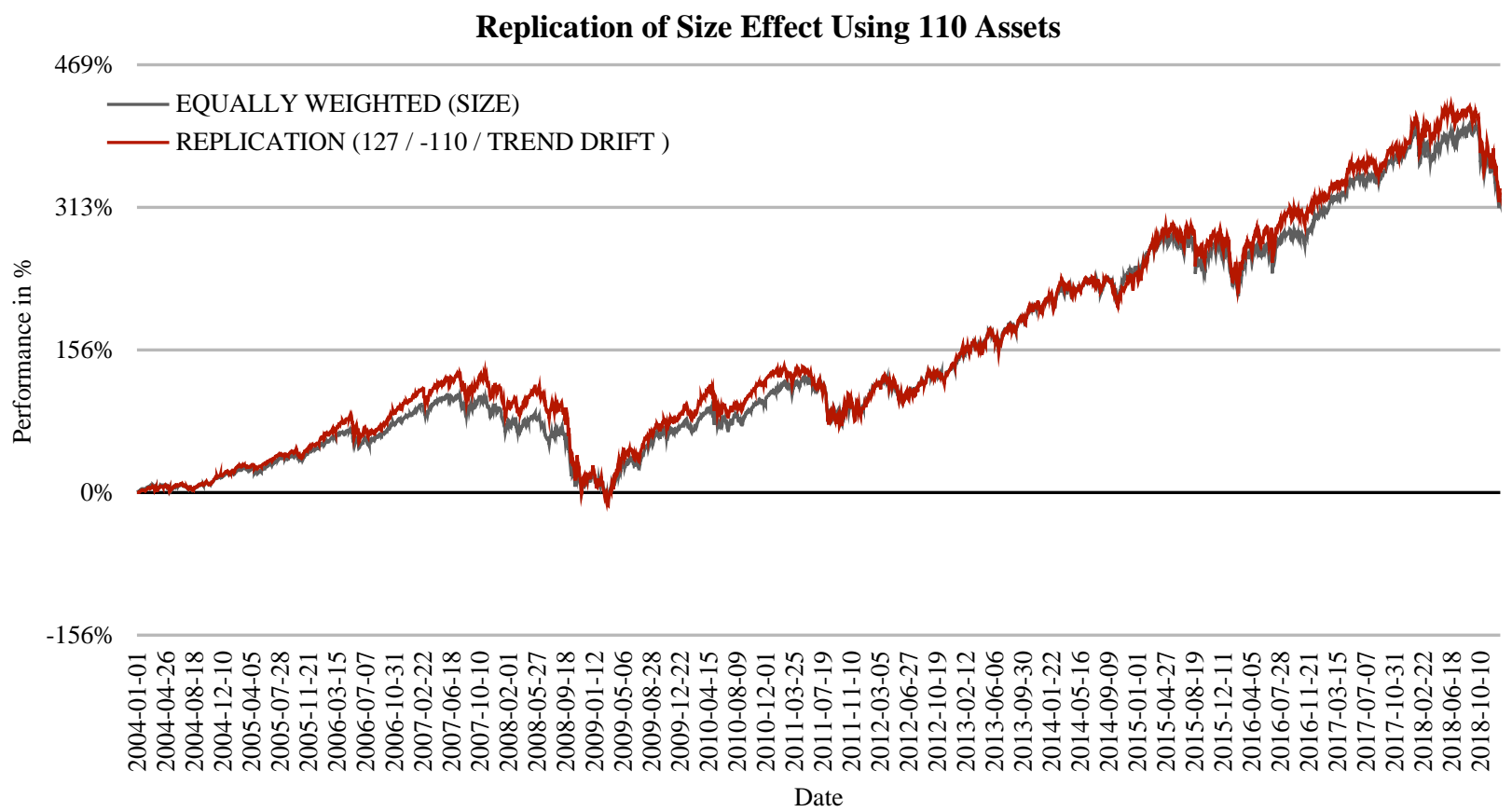

Figure 12. Replication of size effect using 110 assets

Please note that Alquist, Israel and Moskowitz (2018) argued that the size factor ' [...] may not have existed in the first place.' (p. 1) Therefore, we separate that effect from the other analyzed factors.

\subsubsection{Discussion}

It is worth mentioning that the scales found are neither stable nor persistent. Because we assume strong non-stationarity of asset returns, any modifications of the measurement (e.g., the portfolio size, the time interval investigated) lead to different results. However, the described model enables a transfer of factor anomalies into the wavelet domain. Almost every factor $T_{i}$ has an approximation with a linear transfer function $L_{i}$ (having $R_{i}^{2} \geq$ $90 \%$ for every factor $i$ ) with

$$
L_{i}: T_{i} \rightarrow F_{i}
$$

Therefore, we can discuss characteristics in the wavelet domain (using the trend factor $T_{i}$ and the associated (sub-) optimal scales). Using the inverse of $L_{i}$, we are able to relate back to the original factor $F_{i}$. Table 1 summarizes the results and shows that under high statistical certainty, these transfer functions cannot be rejected. However, by focusing on the portfolio distance $D\left(\Gamma, \Gamma^{\prime}, S, t\right)$, these replicated factors are almost identical when compared to the original factors (Note 5):

Table 1. Overview factor replication with trend based ranking

\begin{tabular}{llllllll}
\hline Characteristics & $\begin{array}{c}\text { High } \\
\text { Momentum } \\
(6 \mathrm{M})\end{array}$ & $\begin{array}{c}\text { High } \\
\text { Momentum } \\
(12 \mathrm{M})\end{array}$ & $\begin{array}{c}\text { Low } \\
\text { Volatility } \\
(36 \mathrm{M})\end{array}$ & $\begin{array}{c}\text { Low } \\
\text { Price-EBITDA }\end{array}$ & $\begin{array}{c}\text { High } \\
\text { Dividend } \\
\text { Yield }\end{array}$ & $\begin{array}{c}\text { Low } \\
\text { Price-Book } \\
\text { Ratio }\end{array}$ & Size \\
\hline Drift & 0.0005 & 0.0006 & 0.0002 & 0.0005 & 0.0003 & 0.0004 & 0.0004 \\
Volatility & 0.0117 & 0.0119 & 0.0071 & 0.0131 & 0.0114 & 0.0139 & 0.0117 \\
Risk-Adjusted & 0.0435 & 0.0469 & 0.0335 & 0.0344 & 0.0277 & 0.0309 & 0.0320
\end{tabular}


Return

\begin{tabular}{|c|c|c|c|c|c|c|c|}
\hline Maximum Loss & $-56.49 \%$ & $-53.46 \%$ & $-43.04 \%$ & $-56.37 \%$ & $-59.39 \%$ & $-67.89 \%$ & $-62.85 \%$ \\
\hline Trend Ranking & Drift & Drift & $\begin{array}{l}\text { Inverse } \\
\text { Volatility }\end{array}$ & Drift & Drift & Drift & Drift \\
\hline Scale 1 & 23 & 41 & 89 & 58 & 10 & -93 & 127 \\
\hline Scale 2 & & & & -128 & -10 & -97 & -110 \\
\hline Scale 3 & & & & -39 & & & \\
\hline Alpha & $0.0071 \%$ & $0.0005 \%$ & $0.0014 \%$ & $0.0076 \%$ & $-0.0053 \%$ & $-0.0011 \%$ & $0.0050 \%$ \\
\hline Beta & $90.95 \%$ & $91.70 \%$ & $97.09 \%$ & $88.49 \%$ & $96.54 \%$ & $96.84 \%$ & $85.66 \%$ \\
\hline $\mathrm{R} 2$ & $96.39 \%$ & $96.21 \%$ & $97.73 \%$ & $90.37 \%$ & $88.81 \%$ & $93.10 \%$ & $94.93 \%$ \\
\hline $\begin{array}{l}\text { Portfolio } \\
\text { Distance }\end{array}$ & $0.61 \%$ & $0.67 \%$ & $0.79 \%$ & $3.26 \%$ & $2.59 \%$ & $2.82 \%$ & - \\
\hline
\end{tabular}

The results of our analysis show very clearly that momentum and value are strongly anti-correlated. Based on three arguments value can be seen as a strategy that has an anti-momentum parametrization:

1. Economically, the value effect is based on allocating assets when they are 'cheap', i.e., when stock prices are under pressure.

2. Furthermore the value effect (according to the trend model) is investing in negative scaled-down trends, it can clearly be seen as a risk-driven approach.

3. Third, the momentum crash discussed in Daniel and Moskowitz (2016) for long-short momentum factor portfolios is based on the short side of the portfolio and can be seen as a response to a value market, which we will address in the following sections.

The developed transfer functions $L_{i}$ make clear that for this market and for this time interval under high statistical certainty (expressed by high $R_{i}^{2}$ values), we can discuss phenomena from the wavelet space and refer back. The portfolio distance is in accordance with this view and reveals that the results are not an artifact of in-sample optimization.

\section{Trend-Based Return Model for Asset Returns}

Having now transferred the factors into the wavelet space, we need to address the question of whether this can be viewed as adequate for modeling asset returns. Because we have an explicit trend model and a return-based view, we certainly should not apply a risk-based equilibrium model to test the descriptive power. For the following, we assume that the given factors $F_{i},(i=1, \ldots, n)$ are regressed via

$$
R_{M}(t)=\alpha+\sum_{i=1}^{n} \beta_{i} R_{F_{i}}(t)+\epsilon_{t}
$$

to the market return $R_{M}$.

\subsection{Beta in a Return-Based View}

To compare directly to the capital asset pricing model, we define $\beta_{C A P M, S_{k}}^{\Delta t}$ as the coefficient of the following regression:

$$
R_{s_{k}}(t)=\alpha+\beta_{C A P M, S_{k}}^{\Delta t} R_{M}(t)+\epsilon_{t}
$$

In this model, we measure the sensitivity of a stock return $R_{s_{k}}(t)$ given the market return $R_{M}(t)$. 
Let us assume that we built this factor like the other factors above, i.e., we sort every month according to the individual $\beta_{C A P M, S_{k}}^{\Delta t}$ and take the $10 \%$ decile. The resulting factor $\beta_{C A P M}^{\Delta t}$ is dependent on $\Delta t$.

To determine the ratio of explained market returns, we will use the explanatory power $E P$ defined by

$E P:=1-\frac{\alpha}{\overline{E\left(R_{M}\right)}} \cdot(15)$ Assume that we take the momentum time periods used for the momentum factors above and analyze $\beta_{C A P M}^{6 M}$ and $\beta_{C A P M}^{12 M}$ representing beta estimates over 6 months and 12 months, respectively. We run now the return-based regression from above and find that $\beta_{C A P M}^{6 M}$ and $\beta_{C A P M}^{12 M}$ are indeed good descriptions for this model, as summarized in Table 2.

Table 2. Beta in a return based view

\begin{tabular}{llll}
\hline Characteristics & $\beta_{C A P M}^{6 M}$ & $\beta_{C A P M}^{12 M}$ & $\beta_{C A P M}^{6 M}$ and $\beta_{C A P M}^{12 M}$ \\
\hline Alpha & 0.00003599 & 0.00005978 & 0.00005844 \\
Regression Coefficient (1) & 0.4798 & 0.4882 & 0.0253 \\
Regression Coefficient (2) & & & 0.4628 \\
Market Drift & 0.00018188 & 0.00018188 & 0.00018188 \\
R2 & 0.7938 & 0.7938 & 0.7938 \\
Explanatory Power & $80.21 \%$ & $67.13 \%$ & $67.87 \%$ \\
\hline
\end{tabular}

Table 2 shows that $\beta_{C A P M}^{6 M}$ is the better explanatory variable when compared to $\beta_{C A P M}^{12 M}$, although the $R_{\beta_{C A P M}^{6 M}}^{2}$ is as good as $R_{\beta_{C A P M}^{12 M}}^{2}$. Under the period of 12 months, the explanatory power $E P$ decreases. Now we can combine both in a multiple regression, and we find exactly the opposite: $\beta_{C A P M}^{12 M}$ is the dominating factor since $\beta_{C A P M}^{6 M}$ is close to zero.

However, all three regressions exhibit high $R^{2}$ values, and we use this value as a reference point for the next experiment.

\subsection{Return-Based Factor Review}

We now run several regressions, where we compare our classes of risk and return factors (as categorized in Table 3) and combine them. This combination is extended by the size factor. We finally use the mean reversion approach of Berghorn and Otto (2018) (Note 6) to see how this effect might influence the explanatory power. The results are depicted in Table 3: 
Table 3. Return based factor view

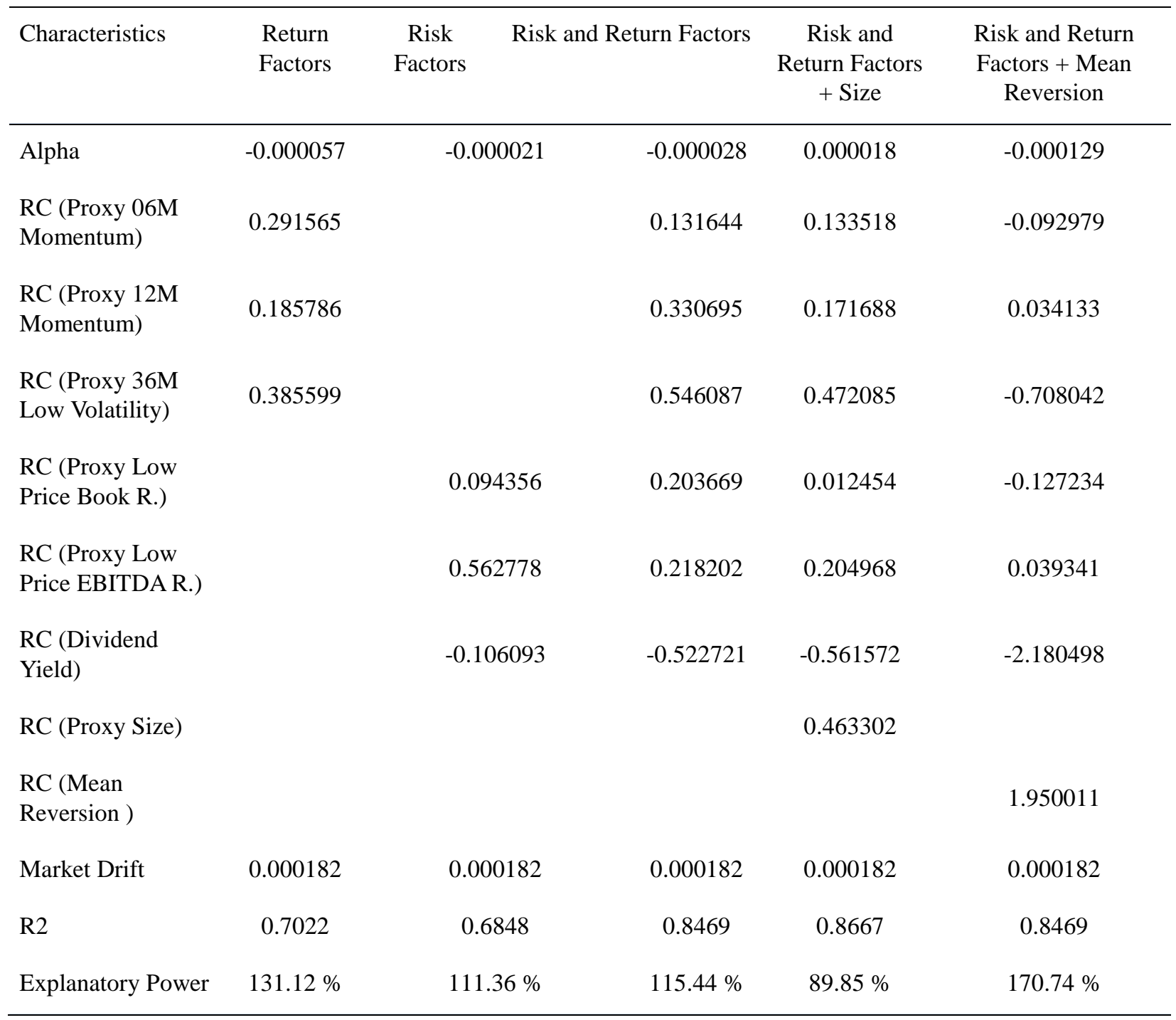

The results show that the return-based strategies (momentum and low volatility combined with the value strategies considered in this work) are highly competitive with the capital asset pricing model, as the value $R^{2}$ are similar compared to the capital asset pricing model.

Furthermore, we see that return-based strategies outperform such that the remaining $\alpha$ is negative and the value of $E P$ exceeds $100 \%$. The same is true for value strategies and for the combination. If we now consider the size effect, then we would obtain a $E P$ describing $90 \%$ of the market returns. However, if we model mean reversion according to Berghorn and Otto (2018), then the EP value exceeds even $170 \%$.

Please note that we explicitly do not analyze whether or not individual regression coefficients are statistically significant. The effects modeled here are discussed in the literature. The only claim that we derive is that these well-documented anomalies are complete in a sense that a good linear model can be found when trying to explain market returns. Consequently, we see estimates over markets and time periods as

$$
\overline{E\left(R_{M}\right)_{\Delta t}}=\alpha+\overline{E\left(R_{\mathbb{F}_{\Delta t}^{+}}-R_{M}\right)_{\Delta t}}-\overline{E\left(R_{\mathbb{F}_{\Delta t}^{-}}-R_{M}\right)_{\Delta t}}+\epsilon
$$

where $\overline{E\left(R_{M}\right)_{\Delta t}}$ denotes the estimate for the market return, $\alpha$ a component that one does not model, and one will find a set of factors $\mathbb{F}_{\Delta t}^{+}$over some period $\Delta t$ that generate excess returns $\overline{E\left(R_{\mathbb{F}_{\Delta t}^{+}}-R_{M}\right)_{\Delta t}}>0$ and find factors 
$\mathbb{F}_{\Delta t}^{-}$that generate underperformance $\overline{E\left(R_{\mathbb{F}_{\Delta t}^{-}}-R_{M}\right)_{\Delta t}}<0$ for a given period $\Delta t$. Essentially, this is a return-based equilibrium model reflecting non-stationarity and views market data as being superimposed by strategies $\mathbb{F}_{\Delta t}^{+}$and $\mathbb{F}_{\Delta t}^{-}$.

This view does not contradict the work of Carhart (1997), who found that the average portfolio manager does not outperform the market. It states only that the strategies as a whole balance out, i.e., there can be a huge in-balance of $\mathbb{F}_{\Delta t}^{+}$and $\mathbb{F}_{\Delta t}^{-}$(Note 5).

How should we model stock markets? Is an asset's $\beta_{C A P M, S_{k}}^{\Delta t}$ - risk factor that is driving returns or are these the trends we used as a model that lead to high $\beta_{C A P M, S_{k}}^{\Delta t}$ values?

Let us assume that for a specific asset $S$, we had information innovations $I_{1}, \ldots, I_{n}$ at discrete times $1, \ldots, n$. If investors react fast on the occurrence of $I_{i}$, then locally, we would assume $\overline{E\left(R_{S}-R_{M} \mid I_{1}, \ldots, I_{i}\right)_{\Delta t}}=0$ for small $\Delta t$. Investors would not be able to estimate when further innovations $I_{j>i}$ occur or how often they will occur in future. This information is exclusive to $S$ and is insider information. However, in hindsight, it is possible to measure trends. Let us assume that all investor reactions were positive and that every event leads to excess returns compared to the market. We are then able to clearly identify trends. At the same time, we would also see high $\beta_{C A P M, S_{k}}^{\Delta t}$ values for this asset $S_{k}$.

\subsection{Investor Reactions}

In the final experiment, we ask whether different factors are 'reacting' (in terms of excess return) to market conditions. Therefore, we assume the following classes of investors:

- Value Investor: Value investors see an opportunity if market conditions led to 'cheap' assets. We will model this phenomenon using moving averages on the market prices $S_{m}$. We investigate a value strategy if $M V A_{200}\left(S_{m}(t)\right)>S_{m}(t)$ and $M V A_{20}\left(S_{m}(t)\right)<S_{m}(t)$, i.e., if the market is in a downturn on a broad scale and corrects on a smaller scale (measured by using moving averages on 200 and 20 business days, respectively). The factor used in the model is the proxy of Price to EBITDA in the wavelet domain.

- Defensive Investor: Defensive investors pursue a low-volatility strategy. As such, we use the constraint that in downturn periods $M V A_{200}\left(S_{m}(t)\right)>S_{m}(t)$ and $M V A_{20}\left(S_{m}(t)\right)>S_{m}(t)$, we use exclusively the 'safest' factor, i.e., low volatility represented by the wavelet trend-based approach.

- Momentum Investor: Momentum investors believe that there are trends in markets and therefore pursue a momentum strategy. We choose the proxy in the wavelet domain to represent 6-month momentum.

We now differentiate various market conditions and analyze factors on the basis of the performance of the last month as follows:

- Upward Market: If $M V A_{200}\left(S_{m}(t)\right)<S_{m}(t)$ and $M V A_{20}\left(S_{m}(t)\right)<S_{m}(t)$, we test low volatility and momentum and choose one of these two factors based on the performance of the last month.

- Downward Market: If $M V A_{200}\left(S_{m}(t)\right)>S_{m}(t)$ and $M V A_{20}\left(S_{m}(t)\right)>S_{m}(t)$, we choose the low volatility factor.

- Correcting Market: If $M V A_{200}\left(S_{m}(t)\right)>S_{m}(t)$ and $M V A_{20}\left(S_{m}(t)\right)<S_{m}(t)$, we test momentum vs. value and choose the factor that had the best performance over the previous month.

This model is a very harsh simplification. However, when tested against other strategies, it is an effective one, as shown in Table 4 and Figure 13: 


\section{Comparison of Strategies "Timing" Factors}

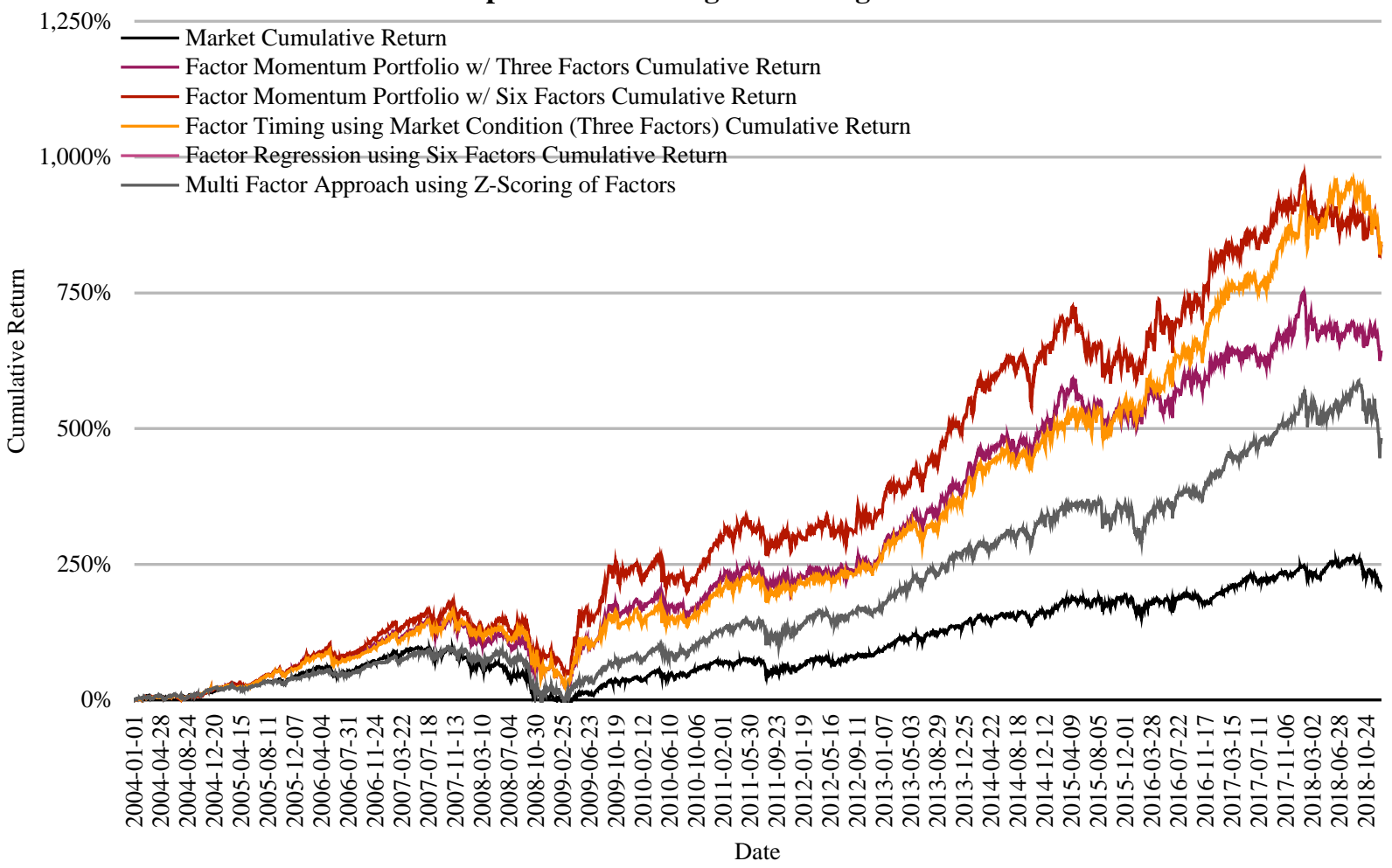

Figure 13. Comparison of strategies "Timing" factors

Table 4. Comparison factor timing strategies (10\% Decile)

\begin{tabular}{llllll}
\hline Characteristics & $\begin{array}{l}\text { Factor Strategy } \\
\text { Portfolio w/ } \\
\text { Three Factors }\end{array}$ & $\begin{array}{l}\text { Factor Strategy } \\
\text { Portfolio w/ Six } \\
\text { Factors }\end{array}$ & $\begin{array}{l}\text { Factor Timing } \\
\text { using Market } \\
\text { Condition } \\
\text { (Three Factors) }\end{array}$ & $\begin{array}{l}\text { Factor Regression } \\
\text { using Six Factors }\end{array}$ & $\begin{array}{l}\text { Multi Factor } \\
\text { Approach } \\
\text { using } \\
\text { Z-Scoring of } \\
\text { Factors (Six } \\
\text { Factors) }\end{array}$ \\
\hline $\begin{array}{l}\text { Value Weighted } \\
\text { Index (\%) }\end{array}$ & $213.26 \%$ & $213.26 \%$ & $213.26 \%$ & $213.26 \%$ & $213.26 \%$ \\
$\begin{array}{l}\text { Value Weighted } \\
\text { Index (\% p.a.) }\end{array}$ & $7.91 \%$ & $7.91 \%$ & $7.91 \%$ & $7.91 \%$ & $7.91 \%$ \\
$\begin{array}{l}\text { Return Factor } \\
\text { Strategy (\%) }\end{array}$ & $643.84 \%$ & $839.07 \%$ & $844.48 \%$ & $496.86 \%$ & $482.89 \%$ \\
$\begin{array}{l}\text { Return Factor } \\
\text { Strategy (\% p.a.) }\end{array}$ & $14.32 \%$ & $16.11 \%$ & $16.16 \%$ & $12.66 \%$ & $12.48 \%$ \\
$\begin{array}{l}\text { Excess Return (\%) } \\
\text { Excess Return (\% }\end{array}$ & $430.58 \%$ & $625.82 \%$ & $631.22 \%$ & $283.61 \%$ & $269.63 \%$ \\
p.a.) & $6.41 \%$ & $8.20 \%$ & $8.24 \%$ & $4.74 \%$ & $4.56 \%$
\end{tabular}




\begin{tabular}{|c|c|c|c|c|c|}
\hline $\begin{array}{l}\text { Volatility Value } \\
\text { Weighted (\% p.a.) }\end{array}$ & $15.18 \%$ & $15.18 \%$ & $15.18 \%$ & $15.18 \%$ & $15.18 \%$ \\
\hline $\begin{array}{l}\text { Volatility Factor } \\
\text { Strategy (\% p.a.) }\end{array}$ & $17.45 \%$ & $18.59 \%$ & $17.47 \%$ & $19.85 \%$ & $19.84 \%$ \\
\hline $\begin{array}{l}\text { Drift Value } \\
\text { Weighted (\%) }\end{array}$ & $0.0292 \%$ & $0.0292 \%$ & $0.0292 \%$ & $0.0292 \%$ & $0.0292 \%$ \\
\hline $\begin{array}{l}\text { Drift Factor } \\
\text { Strategy }(\%)\end{array}$ & $0.0513 \%$ & $0.0573 \%$ & $0.0574 \%$ & $0.0457 \%$ & $0.0451 \%$ \\
\hline $\begin{array}{l}\text { Volatility Value } \\
\text { Weighted (\%) }\end{array}$ & $0.9395 \%$ & $0.9395 \%$ & $0.9395 \%$ & $0.9395 \%$ & $0.9395 \%$ \\
\hline $\begin{array}{l}\text { Volatility Factor } \\
\text { Strategy }(\%)\end{array}$ & $1.0799 \%$ & $1.1507 \%$ & $1.0815 \%$ & $1.2288 \%$ & $1.2279 \%$ \\
\hline $\begin{array}{l}\text { Risk Adjusted } \\
\text { Return Value } \\
\text { Weighted }\end{array}$ & 0.0311 & 0.0311 & 0.0311 & 0.0311 & 0.0311 \\
\hline $\begin{array}{l}\text { Risk Adjusted } \\
\text { Return Factor } \\
\text { Strategy }\end{array}$ & 0.0475 & 0.0498 & 0.0531 & 0.0372 & 0.0367 \\
\hline $\begin{array}{l}\text { Maximal } \\
\text { Drawdown Value } \\
\text { Weighted (\%) }\end{array}$ & $-54.92 \%$ & $-54.92 \%$ & $-54.92 \%$ & $-54.92 \%$ & $-54.92 \%$ \\
\hline $\begin{array}{l}\text { Maximal } \\
\text { Drawdown Factor } \\
\text { Strategy }(\%)\end{array}$ & $-51.10 \%$ & $-47.93 \%$ & $-52.04 \%$ & $-53.44 \%$ & $-53.52 \%$ \\
\hline Alpha & $0.0252 \%$ & $0.0299 \%$ & $0.0316 \%$ & $0.0218 \%$ & $0.0212 \%$ \\
\hline Beta & 0.8932 & 0.9365 & 0.8827 & 0.8188 & 0.8183 \\
\hline Std.Dev. Alpha & $0.0109 \%$ & $0.0119 \%$ & $0.0111 \%$ & $0.0153 \%$ & $0.0153 \%$ \\
\hline Std.Dev. Beta & 0.011567 & 0.012622 & 0.011816 & 0.016309 & 0.016297 \\
\hline t-statistics Alpha & 2.3201 & 2.5219 & 2.8486 & 1.4202 & 1.3826 \\
\hline t-statistics Beta & 77.23 & 74.20 & 74.70 & 50.21 & 50.21 \\
\hline Error Regression & 0.0068 & 0.0074 & 0.0069 & 0.0096 & 0.0096 \\
\hline $\begin{array}{l}\text { Correlation Returns } \\
(\%)\end{array}$ & $77.72 \%$ & $76.47 \%$ & $76.68 \%$ & $62.61 \%$ & $62.61 \%$ \\
\hline R2 & 0.60 & 0.58 & 0.59 & 0.39 & 0.39 \\
\hline Tracking Error (\%) & $0.6869 \%$ & $0.7439 \%$ & $0.7029 \%$ & $0.9731 \%$ & $0.9726 \%$ \\
\hline
\end{tabular}


As shown in Figure 13 and Table 4, the model of investor reactions is comparable to an approach using the momentum factor and a restricted set of six factors. If we regress the model of investor reactions onto the model using the momentum of six factors, we obtain an alpha of $1.999 \mathrm{e}-05$ and a beta value of $9.626 \mathrm{e}-01$. The R2 value is 0.8186 , and the p-value is less than $2.2 \mathrm{e}-16$. Statistically, these values can be viewed as similar.

\section{Conclusions}

The results presented above are based on multi-scale approaches (similar to those of Mandelbrot (1963)) to see whether some important anomalies in finance theory can be understood from a different perspective. As such, we ran examples showing that the data used here exhibit strong 'trending', which can be measured by the Hurst exponent, allowing us to look at the issue with a stationary model: the fractional Brownian motion. Under this model, one would relate to long-term memory. However, if we explicitly model trends using the wavelet transform and a linear trend model at different scales, we examine the issue using a non-stationary multi-scale view, which enables us to test whether stationary models, such as geometric and fractional Brownian motions, have shortcomings in modeling real-world data. We were able to find that trends in stock markets are longer (in terms of business days) and wilder in terms of their variation (in business days) compared to the previously mentioned stationary random processes. We studied the development of trends and concluded that markets certainly react quickly to new information on a day-to-day basis. However, there are situations in which one cannot anticipate available information because such anticipation requires forecasting methods that can establish an aggregated, homogenous investor view that can make long-term forecasts. In these situations, momentum is an approach to measure what is measurable. As such, and consistent with fractional Brownian motions, the deviations can become stronger if the scale widens. In fact, fractional Brownian motions imply inefficient markets on longer-term scales and enable momentum (according to Berghorn (2015) and Berghorn et. al. (2021)).

Combined with previous research and establishing a linear transfer function with some minimal accuracy, we were able to analyze important factor anomalies (such as momentum, low volatility, and value) in a different mathematical space: the wavelet domain. Defining generalized scales (meaning also handling negative ones) in that domain, these factor anomalies have a multi-scale representation and can be seen as overlay-strategies, which strongly supports that markets should be seen as fractal, as first sketched by Mandelbrot (2001). As such, and by interpreting the scales found, momentum and low volatility should not have a risk-based view because they use positive trends, whereas value can be understood as a risk factor, systematically analyzing negative trends.

Addressing non-stationarity, we can now build the argument that momentum and value (as opposite strategies) could be modeled for other markets. As addressed above, momentum can be seen as an approximation to the Haar wavelet transform, which in turn can be seen as an approximation of the best possible wavelet transform that we use in modeling data by trends.

Using this explicit trend model, we invert the EMH and the risk-based view onto these anomalies (as expressed in the multi-factor models). Essentially, we take a return-based view and regress the trend-based factors onto market returns. The accuracy of that regression models has competing characteristics compared to the original capital asset pricing model, which leads to a view in which we assume that certain strategies of investors (as an aggregate) dominate market returns, which can be measured by the momentum factor. We give an example where this is utilized for the momentum, low volatility, and value factors and where we model investor reactions to market conditions. This view is consistent with proposed investor models used in Anderson and Noss (2013), who derive that markets could be seen that way and who propose a simplistic model of investor reactions to arriving new information. These models are essentially dynamical systems (see Peitgen, Jürgens and Saupe (1992)) that allow fundamentally chaotic behavior and fractal structures - the latter is measured by the Hurst exponent.

These models and trend-based models (Berghorn and Otto (2017)) are first attempts to explain certain aspects (mathematically) of characteristics of asset returns. In summary, market returns can be viewed as having fractal characteristics and non-stationarity (trends), as expressed by this work.

Using regression analysis, we assume that this view is equivalent to the capital asset pricing model because it allows an alternative description of market returns. Under this assumption of non-stationary fractal markets, the following ramifications emerge:

- Investors do not have accurate estimations of expected returns and covariances in the long term. This depends on when the parameters are estimated and on the time horizon used for measurement and projection.

- Therefore, there is not a homogenous view in the long term, which is also supported by interpreting market 
returns as different investor strategies that operate on different scales.

- Consequently, the assumptions of Sharpe (1964) under this long-term view are not fulfilled, i.e. the arbitrage argument cannot be made because investors are different and measure different things, leading to different efficient frontiers.

- However, short-term, the story is very different, which can be seen from the fractional Brownian motion model. Short-term trending effects are small and neglectable, and markets can be seen as efficient. The same effect emerges if one uses trends for the analysis.

- From this perspective, one can derive that markets could be seen as 'asymptotically efficient', inefficient on larger scales and approximately efficient on short scales.

We began this work with an overview showing the complexity regarding the EMH. The results are consistent with the debate in academia. One can interpret effects very differently, e.g., Shiller's (1981) long-term view versus Fama's (1995) short-term view. Mathematically, scale matters to that discussion. Viewing effects from a multi-scale, fractal trend perspective, one can easily understand why that factor zoo is present. Under this view in highly competitive markets, investors will always seek strategies that outperform existing ones. What they find will depend on what is being measured and when. In an interview, Fama and Litterman (2012) expressed the following view: 'Of all the potential embarrassments to market efficiency, momentum is the primary one.' (p. 18) and with respect to arguments made in behavioral finance: 'If it's irrational, it should go away, but it doesn't seem to have gone away' (Fama and Litterman (2012), p. 18). This view is strongly related and consistent with the arbitrage argument and risk-based explanations of his previous work. Assuming feedback systems as argued in Anderson and Noss (2013), one can derive that fractal markets will imply factors that in turn feed investments into the market itself, which again enforces fractal structures. This circle argument would undermine the arbitrage argument for long scales and would not allow markets to converge to equilibrium for longer scales.

We looked onto the issue from a certain perspective of signal theory using trends, which is in itself a simplification and approximation of market phenomena. Using regression analysis from statistics, we were able to simplify even further. These simplifications allowed us to view these market characteristics differently, especially from a return-based standpoint. As Mandelbrot and Hudson (2006) put it, 'In economics, there can never be a 'theory of everything. ' But I believe each attempt comes closer to a proper understanding of how markets behave.' (p. 198)

\section{Acknowledgements}

We would like to thank Heinz-Otto Peitgen and Marcel van Leeuwen (DPWT Deutsche Wertpapiertreuhand GmbH, Herzogenaurach, Germany) for their ongoing support and comments.

This work is rooted in comments of Dr. Thomas Zwirner concerning momentum and its relation to the capital asset pricing model. We would like to thank him for approaching us and starting this discussion.

We would want to thank Peter Singer (Fachhochschule Ingolstadt, Germany), who reviewed this work, the argument chain, and the simulation results.

We would like to thank Dr. Kurt Michael Becker for an additional review.

We would also like to thank the Sparkasse Bremen AG for their partnership and for providing an open environment for fostering innovation in finance. We would also like to thank Prof. Dr. Matija Denise Mayer-Fiedrich for offering continuous support and scientific input.

\section{References}

Alquist, R., Israel, R., \& Moskowitz, T. (2018). Fact, Fiction, and the Size Effect. Journal of Portfolio Management, 45(1), 34-61. https://doi.org/10.3905/jpm.2018.1.082

Anderson, N., \& Noss, J. (2013). The Fractal Market Hypothesis and its implications for the stability of financial markets. Bank of England Financial Stability Paper, No. 23. Retrieved from https://ssrn.com/abstract=2338439

Asness, C. S., Moskowitz, T. J., \& Pedersen, L. (2013). Value and Momentum Everywhere. Journal of Finance, 68(3), 929-986. https://doi.org/10.1111/jofi.12021

Asness, C., Frazzini, A., Israel, R., Moskowitz, T. J., \& Pedersen, L. (2015). Size Matters, If You Control Your Junk. Journal of Financial Economics, 129(3), 479-509. https://doi.org/10.1016/j.jfineco.2018.05.006

Bachelier, L. (1900). Théorie de la Spéculation. Annales scientifiques de l'École Normale Supérieure, 3(17), 21-86.

Bandarchuk, P., \& Hilscher, J. (2012). Sources of momentum profits: Evidence on the irrelevance of characteristics. 
Review of Finance, 17(2), 809-845. https://doi.org/10.1093/rof/rfr036

Banz, R. W. (1981). The relationship between return and market value of common stocks. Journal of Financial Economics, 9(1), 3-18. https://doi.org/10.1016/0304-405X(81)90018-0

Basu S. (1983). The relationship between earnings yield, market value, and return for NYSE common stocks: Further evidence. Journal of Financial Economics, 12(1), 129-156. https://doi.org/10.1016/0304-405X(83)90031-4

Berghorn, W. (2015). Trend Momentum. Quantitative Finance, 15(2), 261-284. https://doi.org/10.1080/14697688.2014.941912

Berghorn, W., \& Otto, S. (2017a). Mandelbrot Market-Model and Momentum. International Journal of Financial Research, 8(3). https://doi.org/10.5430/ijfr.v8n3p1

Berghorn, W., Schulz, M. T., Vogl, M., \& Otto, S. (2021). Trend Momentum II: Driving Forces of Low Volatility and Momentum. International Journal of Financial Research, 12(3), 300-319. https://doi.org/10.5430/ijfr.v12n3p300

Black, F., Jensen, M., \& Scholes, M. S. (1972). The Capital Asset Pricing Model: Some Empirical Findings. In Jensen, M. (Ed.), Studies in the Theory of Capital Markets (pp. 79-124). Praeger Publishers, New York.

Black, F., \& Scholes, M. (1973). The Pricing of Options and Corporate Liabilities. Journal of Political Economy, 81(3), 637-654. https://doi.org/10.1086/260062

Blitz, D., Hanauer, M. X., Vidojevic, M., \& van Vliet, P. (2016). Five Concerns with the Five-Factor Model. https://doi.org/10.2139/ssrn.2862317

Campbell, J. Y. (2014). Empirical Asset Pricing: Eugene Fama, Lars Peter Hansen, and Robert Shiller. Scandinavian Journal of Economics, 116(3), 593-634. https://doi.org/10.1111/sjoe.12070

Carhart, M. M. (1997). On persistence in mutual fund performance. Journal of Finance, 52(1), 57-82.

Chan, L. K. C., Jegadeesh, N., \& Lakonishok, J. (1996). Momentum Strategies. Journal of Finance, 51(5), 1681-1713. https://doi.org/10.1111/j.1540-6261.1996.tb05222.x

Chan, L. K., Yasushi, H., \& Lakonishok, J. (1991). Fundamentals and stock returns in Japan. Journal of Finance, 46(5), 1739-1789. https://doi.org/10.1111/j.1540-6261.1991.tb04642.x

Charest, G. (1978). Dividend information, stock returns and market efficiency II. Journal of Financial Economics, 6(2-3), 297-330. https://doi.org/10.1016/0304-405X(78)90033-8

Cooper, M. J., Gutierrez, R. C., \& Hameed, A. (2004). Market states and momentum. Journal of Finance, 59(3), 1345-1365. https://doi.org/10.1111/j.1540-6261.2004.00665.x

Cootner, P. H. (1964). Stock Prices: Random vs. Systematic Changes. Industrial Management Review, 231-252.

Cullen, A. C., \& Frey, H. C. (1999). Probabilistic techniques in exposure assessment. Plenum Press, Springer US, pp. 81-155.

Daniel, K., \& Moskowitz, T. J. (2016). Momentum crashes. Journal of Financial Economics, 122(2), 221-247, https://doi.org/10.1016/j.jfineco.2015.12.002

DeBondt, W. F. M., \& Thaler, R. H. (1985). Does the Stock Market Overreact?. Journal of Finance, 40(3), 793-805.

DeBondt, W. F. M., \& Thaler, R. H. (1987). Further evidence on investor overreaction and stock market seasonality. Journal of Finance, 42(3), 557-581. https://doi.org/10.1111/j.1540-6261.1987.tb04569.x

Dhillon, U. S., \& Johnson, H. (1994). The Effect of Dividend Changes on Stock and Bond Prices. Journal of Finance, 49(1), 281-289. https://doi.org/10.1111/j.1540-6261.1994.tb04430.x

Einstein, A. (1905). Über die von der molekularkinetischen Theorie der Wärme geforderte Bewegung von in ruhenden Flüssigkeiten suspendierten Teilchen. Annalen der Physik, 322(8), 549-560.

Evertsz, C., Berkner, K., \& Berghorn, W. (1998). A local multiscale characterization of edges applying the wavelet transform. Proc. Nato A.S.I, Fractal Image Encoding and Analysis. https://doi.org/10.1007/978-3-662-03512-2_15

Fama, E. F. (1965). The Behavior of Stock Market Prices. Journal of Business, 38(1), 34-105.

Fama, E. F. (1970). Efficient Capital Markets: A Review of Theory and Empirical Work. Journal of Finance, 25(2), 383-417. https://doi.org/10.2307/2325486 
Fama, E. F. (1995). Random Walks in Stock Market Prices. Financial Analysts Journal, 51(1), 75-80.

Fama, E. F., \& French, K. R. (1988). Dividend yields and expected stock returns. Journal of Financial Economics, 22(1), 3-25. https://doi.org/10.1016/0304-405X(88)90020-7

Fama, E. F., \& French, K. R. (1992). The cross-section of expected stock returns. Journal of Finance, 47(2), 427-465. https://doi.org/10.1111/j.1540-6261.1992.tb04398.x

Fama, E. F., \& French, K. R. (2008). Dissecting Anomalies. Journal of Finance, 63(4), 1653-1678. https://doi.org/10.1111/j.1540-6261.2008.01371.x

Fama, E. F., \& French, K. R. (2012). Size, Value, and Momentum in International Stock Returns. Journal of Financial Economics, 105(3), 457-472. https://doi.org/10.1016/j.jfineco.2012.05.011

Fama, E. F., \& French, K. R. (2015). A Five-Factor Asset Pricing Model. Journal of Financial Economics, 116(1), 1-22. https://doi.org/10.1016/j.jfineco.2014.10.010

Fama, E. F., \& Litterman, R. (2012). An Experienced View on Markets and Investing. Financial Analysts Journal, 68(6), 15-19. https://doi.org/10.2469/faj.v68.n6.1

Fama, E. F., \& MacBeth, J. D. (1973). Risk, Return, and Equilibrium: Empirical Tests. Journal of Political Economy, 81(3), 607-636. https://doi.org/10.1086/260061

Fama, E. F., Fisher, L., Jensen, M. C., \& Roll, R. (1969). The Adjustment of Stock Prices to New Information. International Economic Review, 10(1), 1-21. https://doi.org/10.2307/2525569

Feng, G., Giglio, S., \& Xiu, D. (2017). Taming the Factor Zoo: A Test of New Factors. Journal of Finance, 75(3), 1327-1370. https://doi.org/10.1111/jofi.12883

Frazzini, A., \& Pedersen, L. H. (2014). Betting against beta. Journal of Financial Economics, 111(1), 1-25. https://doi.org/10.1016/j.jfineco.2013.10.005

Friend, I., \& Blume, M. (1970). Measurement of Portfolio Performance under Uncertainty. The American Economic Review, 60(4), 561-575. Retrieved from http://www.jstor.org/stable/1818402

George, T. J., \& Hwang, C.-Y. (2004). The 52-week high and momentum investing. Journal of Finance, 59(5), 2145-2176. https://doi.org/10.1111/j.1540-6261.2004.00695.x

Granger, C. W. J., \& Morgenstern, O. (1963). Spectral Analysis of New York Stock Market Prices. Kyklos, 16(1), 1-27. https://doi.org/10.1111/j.1467-6435.1963.tb00270.x

Grinblatt, M., Titman, S., \& Wermers, R. R. (1994). Momentum Investment Strategies, Portfolio Performance, and Herding: A Study of Mutual Fund Behavior. Retrieved from http://ssrn.com/abstract=5686

Grundy, B. D., \& Martin, J. S. (2001). Understanding the Nature of the Risks and the Source of the Rewards to Momentum Investing. Review of Financial Studies, 14(1), 29-78. https://doi.org/10.1093/rfs/14.1.29

Gupta, T., \& Kelly, B. (2019). Factor Momentum Everywhere. Journal of Portfolio Management, 45(3), 13-36.

Haugen, R., \& Baker, N. L. (1996). Commonality in the determinants of expected stock returns. Journal of Financial Economics, 41(3), 401-439. https://doi.org/10.1016/0304-405X(95)00868-F

Haugen, R., \& Heins, A. (1975). Risk and the Rate of Return on Financial Assets: Some Old Wine in New Bottles. Journal of Financial and Quantitative Analysis, 10(5), 775-784. https://doi.org/10.2307/2330270

Hong, H., Lim, T., \& Stein, J. C. (2000). Bad News Travels Slowly: Size, Analyst Coverage, and the Profitability of Momentum Strategies. Journal of Finance, 55(1), 265-295. https://doi.org/10.1111/0022-1082.00206

Hooke, R., \& Jeeves, T. A. (1961). Direct search solution of numerical and statistical problems. Journal of the ACM, 8(2), 212-229. https://doi.org/10.1145/321062.321069

Jacobs, H., \& Weber, M. (2013). Losing sight of the trees for the forest? Attention allocation and anomalies. https://doi.org/10.2139/ssrn.2023539

Jegadeesh, N., \& Titman, S. (2001). Profitability of Momentum Strategies: An Evaluation of Alternative Explanations. Journal of Finance, 56(2), 699-720. https://doi.org/10.1111/0022-1082.00342

Jegadeesh, N. (1990). Evidence of predictable behavior of security returns. Journal of Finance, 45(3), 881-898.

Jegadeesh, N., \& Titman, S. (1993). Returns to buying winners and selling losers: Implications for stock market efficiency. Journal of Finance, 48(1), 65-91. https://doi.org/10.1111/j.1540-6261.1993.tb04702.x 
Kahneman, D. (2011). Thinking Fast and Slow. Allen Lane.

Keim, D. B. (1983). Size-related anomalies and stock return seasonality. Journal of Financial Economics, 12(1), 13-32. https://doi.org/10.1016/0304-405X(83)90025-9

Kendall, M. G., \& Hill, A. B. (1953). The Analysis of Economic Time Series. Journal of the Royal Statistical Society, 116(1), 11-34. https://doi.org/10.2307/2980947

Lee, C. M. C., \& Swaminathan, B. (2000). Price Momentum and Trading Volume. Journal of Finance, 55(5), 2017-2069. https://doi.org/10.1111/0022-1082.00280

Liew, J. K.-S., \& Vassalou, M. (1999). Can Book-to-Market, Size, and Momentum Be Risk Factors That Predict Economic Growth?. https://doi.org/10.2139/ssrn.159293

Lintner, J. (1965). The Valuation of Risk Assets and the Selection of Risky Investments in Stock Portfolios and Capital Budgets. Review of Economics and Statistics, 47(1), 13-37. https://doi.org/10.2307/1924119

Lo, A. W., \& McKinlay, A. C. (1998). Stock market prices do not follow random walks: evidence from a simple specification test. Review of Financial Studies, 1(1), 41-66. https://doi.org/10.1093/rfs/1.1.41

Louis, A. K., Maaß, P., \& Rieder, A. (1994). Wavelets. B.G. Teubner, Stuttgart.

Mandelbrot, B. (1963). The Variation of Certain Speculative Prices. Journal of Business, 36(4), 394-419.

Mandelbrot, B. (1967). How Long Is the Coast of Britain? Statistical Self-Similarity and Fractional Dimension. Science, 156(3775), 636-638. https://doi.org/10.1126/science.156.3775.636

Mandelbrot, B. (1972). Correction of an Error in "The Variation of Certain Speculative Prices" (1963). Journal of Business, 45(4), 542-543. https://doi.org/10.1086/295487

Mandelbrot, B. B. (2001). Scaling in financial prices. Quantitative Finance, 1(6), 427-440. https://doi.org/10.1088/1469-7688/1/6/306

Mandelbrot, B. B., \& Hudson, R. L. (2006). The (Mis) Behaviour of Markets: A Fractal View of Financial Turbulence. Profile Books.

Mandelbrot, B. B., \& Van Ness, J. W. (1968). Fractional Brownian Motions, Fractional Noises and Applications. Society for Industrial and Applied Mathematics Review, 10(4), 422-437. https://doi.org/10.1137/1010093

Markowitz, H. M. (1952). Portfolio Selection. Journal of Finance, 7(1), 77-91.

Moore, A. (1962). A Statistical Analysis of Common Stock Prices, Graduate School of Business. University of Chicago.

Moskowitz, T. J., \& Grinblatt, M. (1999). Do Industries Explain Momentum?. Journal of Finance, 54(4), 1249-1290.

Moskowitz, T. J., Ooi, Y. H., \& Pedersen, L. H. (2010). Time series momentum. Journal of Financial Economics, 104(2), 228-250. https://doi.org/10.1016/j.jfineco.2011.11.003

Novy-Marx, R. (2012). Is momentum really momentum?. Journal of Financial Economics, 103(3), $429-453$.

Novy-Marx, R. (2015). Fundamentally, Momentum is Fundamental Momentum. NBER Working Paper No. 20984. https://doi.org/10.3386/w20984

Okunev, J., \& White, D. (2003). Do momentum-based strategies still work in foreign currency markets?. Journal of Financial and Quantitative Analysis, 38(2), 425-447. https://doi.org/10.2307/4126758

Peitgen, H. O., Jürgens, H., \& Saupe, D. (1992). Chaos and Fractals - New Frontiers of Science. Springer-Verlag New York, Inc. https://doi.org/10.1007/978-1-4757-4740-9

Peters, E. (1989). Fractal Structure in Capital Markets. Financial Analysist Journal, 45(4), 32-37.

Pontiff, J., \& Schall, L. D. (1998). Book-to-market ratios as predictors of market returns. Journal of Financial Economics, 49(2), 141-160. https://doi.org/10.1016/S0304-405X(98)00020-8

Ramsey, J. B. (1999). The contribution of wavelets to the analysis of economic and financial data. Philosophical Transactions: Mathematical, Physical and Engineering Sciences, 357(1760), 2593-2606.

Ramsey, J. B. (2002). Wavelets in Economics and Finance: Past and Future. Studies in Nonlinear Dynamics \& Econometrics, 6(3), 1-29. https://doi.org/10.2202/1558-3708.1090

Ramsey, J. B., Usikov, D., \& Zaslavsky, G. (1995). An analysis of U.S. Stock Price Behavior Using Wavelets. 
Fractals, 3(2), 377-389. https://doi.org/10.1142/S0218348X95000291

Rice, J. A. (1995). Mathematical Statistics and Data Analysis. Duxbury Advanced Series.

Rosenberg, B., Reid, K., \& Lanstein, R. (1985). Persuasive evidence of market inefficiency. Journal of Portfolio Management, 11(3), 9-17. https://doi.org/10.3905/jpm.1985.409007

Ross, S. A. (1976). The arbitrage theory of capital asset pricing. Journal of Economic Theory, 13(3), 341-360.

Rouwenhorst, K. G. (1998). International momentum strategies. Journal of Finance, 53(1), 267-284. https://doi.org/10.1111/0022-1082.95722

Schiereck, D., De Bondt, W., \& Weber, M. (1999). Contrarian and momentum strategies in Germany. Financial Analysts Journal, 55, 104-116. https://doi.org/10.2469/faj.v55.n6.2317

Sharpe, W. (1964). Capital Asset Prices: A Theory of Market Equilibrium under Conditions of Risk. Journal of Finance, 19(3), 425-442. https://doi.org/10.1111/j.1540-6261.1964.tb02865.x

Shiller, R. J. (1981). The Use of Volatility Measures in Assessing Market Efficiency. Journal of Finance, 36(2), 291-304. https://doi.org/10.1111/j.1540-6261.1981.tb00441.x

Shiller, R. J. (2003). From Efficient Markets Theory to Behavioral Finance. Journal of Economic Perspectives, 17(1), 83-104. https://doi.org/10.1257/089533003321164967

Stattman, D. (1980). Book values and stock returns. The Chicago MBA: A Journal of Selected Papers, 4, 25-45.

Stevenson, R. A., \& Bear, R. M. (1970). Commodity Futures: Trends or Random Walks. Journal of Finance, 25(1), 65-81. https://doi.org/10.1111/j.1540-6261.1970.tb00414.x

Taylor, S. J. (1962). Tests of the Random Walk Hypothesis against a Price-Trend Hypothesis. Journal of Finance and Quantitative Analysis, 17(1), 37-61. https://doi.org/10.2307/2330928

Thaler, R. H. (2015). Misbehaving: The making of behavioral economics. New York, W W Norton \& Co.

Villasenor, J., Belzer, B., \& Liao, J. (1995). Wavelet Filter Evaluation for Image Compression. IEEE Transactions on Image Processing, 4(8), 1053-1060. https://doi.org/10.1109/83.403412

\section{Notes}

Note 1. This approach is applied if two or more characteristics are measured. Z-scoring is normalizing the list of characteristics by subtracting the mean of that whole set of characteristics and then dividing that value by the standard deviation of that set. The final score has a zero mean and a standard deviation of one.

Note 2. The principle states that the only function that is optimal in the time domain and the frequency domain is the Gaussian. This function is invariant under spectral analysis.

Note 3. Please note in Figures 2 and 3 that the measurements for geometric and fractional Brownian motions are almost identical and overlap in the figures.

Note 4. Technically, we eliminate all assets where the number of price records is less than $261 \times 5$, assuming 261 stock market days on average per year.

Note 5. Based on the scales found, we segment the factors in three classes, namely, - return-based factors\| having solely positive scales in their replication, - risk-based factors $\|$ having negative scales, and the size effect.

Note 6. Berghorn and Otto (2018) showed that the elimination of "trends" evaluated by 6-month momentum strategies leads to mean reverting markets if one uses the Hurst exponent as a measure.

Note 7. This notation is very similar to the notation of Ross (1976). However, the arbitrage pricing theory is a risk-based model.

\section{Copyrights}

Copyright for this article is retained by the author(s), with first publication rights granted to the journal.

This is an open-access article distributed under the terms and conditions of the Creative Commons Attribution license (http://creativecommons.org/licenses/by/4.0/). 